Cochrane Database of Systematic Reviews

\title{
Percutaneous vascular interventions versus intravenous thrombolytic treatment for acute ischaemic stroke (Review)
}

Lindekleiv H, Berge E, Bruins Slot KMH, Wardlaw JM

Lindekleiv H, Berge E, Bruins Slot KMH, Wardlaw JM.

Percutaneous vascular interventions versus intravenous thrombolytic treatment for acute ischaemic stroke.

Cochrane Database of Systematic Reviews 2018, Issue 10. Art. No.: CD009292.

DOI: 10.1002/14651858.CD009292.pub2.

www.cochranelibrary.com

Percutaneous vascular interventions versus intravenous thrombolytic treatment for acute ischaemic stroke 
TABLE OF CONTENTS

HEADER 1

ABSTRACT

PLAIN LANGUAGE SUMMARY

SUMMARY OF FINDINGS

BACKGROUND

OBJECTIVES

METHODS

RESULTS

Figure 1.

Figure 2.

Figure 3.

DISCUSSION

AUTHORS' CONCLUSIONS

ACKNOWLEDGEMENTS

REFERENCES

CHARACTERISTICS OF STUDIES

DATA AND ANALYSES

Analysis 1.1. Comparison 1 Percutaneous vascular interventions versus intravenous thrombolytic treatment for acute ischaemic stroke, Outcome 1 Modified Rankin scale score 0-2.

Analysis 1.2. Comparison 1 Percutaneous vascular interventions versus intravenous thrombolytic treatment for acute ischaemic stroke, Outcome 2 Modified Rankin scale score, continuous.

Analysis 1.3. Comparison 1 Percutaneous vascular interventions versus intravenous thrombolytic treatment for acute ischaemic stroke, Outcome 3 All-cause death at the end of follow-up.

Analysis 1.4. Comparison 1 Percutaneous vascular interventions versus intravenous thrombolytic treatment for acute ischaemic stroke, Outcome 4 All-cause death within 14 days.

Analysis 1.5. Comparison 1 Percutaneous vascular interventions versus intravenous thrombolytic treatment for acute ischaemic stroke, Outcome 5 Symptomatic intracranial haemorrhages within first 14 days.

APPENDICES

WHAT'S NEW

CONTRIBUTIONS OF AUTHORS

DECLARATIONS OF INTEREST

SOURCES OF SUPPORT

DIFFERENCES BETWEEN PROTOCOL AND REVIEW

INDEX TERMS 
[Intervention Review]

\section{Percutaneous vascular interventions versus intravenous thrombolytic treatment for acute ischaemic stroke}

Haakon Lindekleiv¹, Eivind Berge², Karsten MH Bruins Slot², Joanna M Wardlaw³

1 University Hospital of North Norway, Tromsø, Norway. 2Department of Internal Medicine, Oslo University Hospital, Oslo, Norway.

${ }^{3}$ Centre for Clinical Brain Sciences, University of Edinburgh, Edinburgh, UK

Contact address: Haakon Lindekleiv, University Hospital of North Norway, Tromsø, NO-9018, Norway. haakon.lindekleiv@gmail.com.

Editorial group: Cochrane Stroke Group.

Publication status and date: Edited (no change to conclusions), published in Issue 11, 2018.

Citation: Lindekleiv $\mathrm{H}$, Berge E, Bruins Slot KMH, Wardlaw JM. Percutaneous vascular interventions versus intravenous thrombolytic treatment for acute ischaemic stroke. Cochrane Database of Systematic Reviews 2018, Issue 10. Art. No.: CD009292. DOI: 10.1002/14651858.CD009292.pub2.

Copyright @ 2018 The Cochrane Collaboration. Published by John Wiley \& Sons, Ltd.

\section{A B S T R A C T}

\section{Background}

Most ischaemic strokes are caused by blockage of a cerebral artery by a thrombus. Intravenous administration of recombinant tissue plasminogen activator given within 4.5 hours is now standard treatment for this condition. Percutaneous vascular interventions use an intra-arterial, mechanical approach for thrombus disruption or removal (thrombectomy). Recent randomised trials indicate that percutaneous vascular interventions are superior to usual care (usual care usually included intravenous thrombolysis). However, intravenous thrombolysis was usually given in both arms of the trial and there was a lack of direct comparison of percutaneous vascular interventions with intravenous thrombolysis.

\section{Objectives}

To assess the effectiveness and safety of percutaneous vascular interventions compared with intravenous thrombolytic treatment for acute ischaemic stroke.

\section{Search methods}

We searched the Cochrane Stroke Group Trials Register (last search: August 2018). In addition, in September 2017, we searched the following electronic databases: CENTRAL, MEDLINE, Embase, and Science Citation Index; and Stroke Trials Registry, and US National Institutes of Health Ongoing Trials Register, ClinicalTrials.gov.

\section{Selection criteria}

Randomised controlled trials (RCTs) that directly compared a percutaneous vascular intervention with intravenous thrombolytic treatment in people with acute ischaemic stroke.

\section{Data collection and analysis}

Two review authors applied the inclusion criteria, extracted data, and assessed risk of bias. We obtained both published and unpublished data. We assessed the quality of the evidence using the GRADE approach.

\section{Main results}

We included four trials with 450 participants. Data on functional outcome and death at end of follow-up were available for 443 participants from three trials. Compared with intravenous thrombolytic therapy, percutaneous vascular intervention did not improve the proportion of participants with good functional outcome (modified Rankin Scale score 0 to 2, risk ratio (RR) $1.01,95 \%$ confidence interval (Cl) 0.82 to $1.25, \mathrm{P}=0.92$ ). The quality of evidence was low (outcome assessment was blinded, but not the treating physician or participants). At the 
end of follow-up, there was a non-significant increase in the proportion of participants who died in the percutaneous vascular intervention group ( $\mathrm{RR} 1.34,95 \% \mathrm{Cl} 0.84$ to $2.14, \mathrm{P}=0.21$ ). The quality of evidence was low (wide confidence interval). There was no difference in the proportion of participants with symptomatic intracranial haemorrhages between the intervention and control groups (RR $0.99,95 \% \mathrm{Cl}$ 0.50 to $1.95, \mathrm{P}=0.97$ ). The quality of evidence was low (wide confidence interval). Data on vascular status (recanalisation rate) were only available for seven participants from one trial; we considered this inadequate for statistical analyses.

\section{Authors' conclusions}

The present review directly compared intravenous thrombolytic treatment with percutaneous vascular interventions for ischaemic stroke. We found no evidence from RCTs that percutaneous vascular interventions are superior to intravenous thrombolytic treatment with respect to functional outcome. Quality of evidence was low (outcome assessment was blinded, but not the treating physician or participants). New trials with adequate sample sizes are warranted because of the rapid development of new techniques and devices for such interventions.

\section{PLAIN LANGUAGESUMMARY}

\section{Treatments through the artery versus clot-dissolving drugs for the early treatment of stroke}

\section{Review question}

Are there differences in the safety and effectiveness of treatments delivered into the blocked artery (percutaneous vascular interventions) and clot-dissolving drugs (intravenous thrombolysis) in the early treatment of stroke.

\section{Background}

Most strokes are caused by a blockage of an artery in the brain by a blood clot. Prompt treatment with clot-dissolving drugs (thrombolysis) can restore blood flow and prevent brain damage. The development of treatments delivered through a tube into the artery (percutaneous vascular interventions) has led to new possibilities in the treatment of stroke. This approach gives direct access to the blood clot, which can be mechanically removed or dissolved. Despite widespread use of these treatments it is unclear whether they are more effective and safe than clot-dissolving drugs given by injection (intravenous thrombolysis).

\section{Study characteristics}

We included four trials with 450 participants randomised to either percutaneous vascular intervention or clot-dissolving drugs given by injection.

\section{Search date}

The evidence is current as of September 2017.

\section{Key results}

Compared with clot-dissolving drugs, percutaneous vascular interventions did not increase the chance of making a good recovery by the end of the trial. There was no significant increase in the risk of dying or of suffering a brain bleed. New, larger trials are needed, particularly because of the rapid development of new techniques and devices for percutaneous vascular interventions.

\section{Quality of the evidence}

We judged the quality of the evidence to be low because of the limited amount of trial information available. 


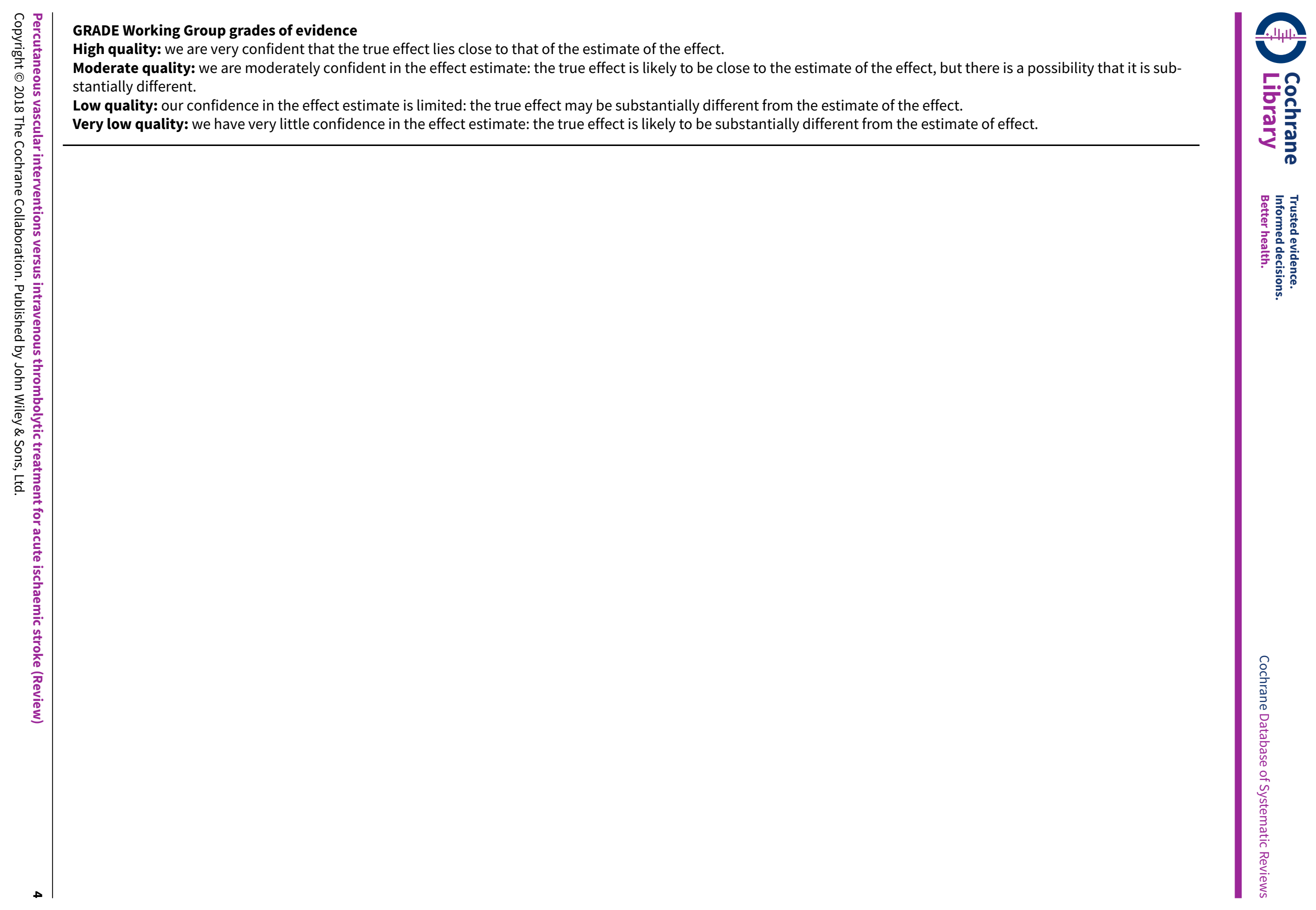




\section{B A C K G R O U N D}

\section{Description of the condition}

Ischaemic stroke is one of the major causes of death and disability worldwide (Strong 2007). Stroke represents a substantial personal and financial burden on society, which most likely will increase during the coming decades as a result of ageing populations (Rosamund 2008; Strong 2007).

Most ischaemic strokes are caused by the blockage of a cerebral artery by a thrombus. Thrombolytic treatment with pharmacological agents aims to dissolve the thrombus in the cerebral artery, leading to recanalisation and restoration of blood flow and improved functional outcome.

Prompt intravenous administration of recombinant tissue plasminogen activator (rt-PA) has been the standard treatment for selected patients with acute ischaemic stroke and is currently the treatment of choice within 4.5 hours of stroke onset (Adams 2007; Del Zoppo 2009; Emberson 2014; ESO 2009; Wardlaw 2009).

Thrombolytic agents can also be administered directly at the site of the occluded cerebral artery, and the rapidly developing field of mechanical clot disruption offers alternative approaches to achieve reperfusion in acute ischaemic stroke. Recent randomised trials indicate that percutaneous vascular interventions are superior to usual care (usual care usually included intravenous thrombolysis; EXTEND-IA 2015; DAWN 2018; DEFUSE 3 2018; MR CLEAN 2015; REVASCAT 2015; SWIFT PRIME 2015). However, intravenous thrombolysis was usually given in both arms of the trial and so there is a lack of direct comparison of percutaneous vascular interventions with intravenous thrombolysis.

\section{Description of the intervention}

Percutaneous vascular interventions are intra-arterial stroke therapies that use a mechanical device for thrombus disruption or removal. The intervention may consist of manipulation of the microcatheter tip/guidewire inside the thrombus, or it may include use of devices that can be divided into five different categories.

- Thrombectomy devices are devices that retrieve a thrombus.

- Thrombus disruption devices use a guide-wire or snare to mechanically fragment a thrombus.

- Thromboaspiration devices use a microcatheter or guiding catheter to aspirate the thrombus.

- Stent devices are expandable scaffolds that entrap the thrombus between the stent and the blood vessel wall.

- Sonothrombolysis devices use ultrasonic vibrations to dissolve the thrombus.

These techniques are often combined with intra-arterial injection of thrombolytic drugs.

Intravenous thrombolytic drugs are now standard treatment of acute ischaemic stroke. The thrombolytic drug alteplase (a recombinant tissue plasminogen activator: rt-PA) has been licensed for use within 4.5 hours after onset of stroke in the USA, Canada, and most European countries. Other types of intravenous thrombolytic drugs include urokinase, recombinant pro-urokinase, streptokinase, and other recombinant tissue plasminogen activators such as duteplase, lumbrokinase, tenecteplase, reteplase, and desmoteplase.

\section{How the intervention might work}

Percutaneous vascular interventions for acute ischaemic stroke aim to recanalise the occluded artery and restore perfusion to ischaemic brain parenchyma.

\section{Why it is important to do this review}

Percutaneous vascular interventions may be used as primary or adjunctive treatment strategies in acute ischaemic stroke and could have several potential advantages over pharmacological thrombolytics. First, these interventions may lead to a lower risk of intracranial haemorrhage and could provide improved recanalisation compared with pharmacological thrombolysis and further minimise ischaemic cerebral damage (Menon 2015). Second, they could extend the time window for treatment beyond 4.5 hours, which is the time window for intravenous rt-PA treatment. Last, percutaneous interventions could be used in patients who have contraindications to pharmacological agents (e.g. abnormal haemostasis or recent surgery).

There are also several potential disadvantages of percutaneous vascular interventions, for example the technical difficulties and the extra time that elapses before treatment can start, the need for centres with proper equipment and expertise, complications related to trauma to the vasculature (e.g. dissection, perforation, or rupture), or fragmentation of the thrombus causing distal artery occlusion.

Recent randomised trials indicate that percutaneous vascular interventions are superior to usual care (usual care usually included intravenous thrombolysis; DAWN 2018; DEFUSE 3 2018; EXTENDIA 2015; MR CLEAN 2015; REVASCAT 2015; SWIFT PRIME 2015). However, intravenous thrombolysis was usually given in both arms of the trial and there is a lack of direct comparison of percutaneous vascular interventions with intravenous thrombolysis.

A direct comparison of these two treatments might help clinicians in selecting the best treatment option for people with acute ischaemic stroke. We therefore aimed to perform a systematic review of all RCTs that directly compared percutaneous vascular interventions with intravenous thrombolytic treatment.

\section{OB JECTIVES}

To assess the effectiveness and safety of percutaneous vascular interventions compared with intravenous thrombolytic treatment for acute ischaemic stroke.

\section{METHODS}

\section{Criteria for considering studies for this review}

\section{Types of studies}

Randomised controlled trials (RCTs), that directly compared a percutaneous vascular intervention with intravenous thrombolytic treatment in people with acute ischaemic stroke. 


\section{Types of participants}

People with acute ischaemic stroke who were eligible for treatment with an intravenous thrombolytic agent or a percutaneous vascular intervention.

\section{Types of interventions}

All percutaneous arterial endovascular techniques aimed at revascularisation in acute ischaemic stroke, including the use of the following devices:

- thrombectomy (retriever devices);

- thromboaspiration;

- mechanical fragmentation of the thrombus;

- intra-arterial sonothrombolysis.

Intra-arterial thrombolytic drugs may be given in addition to any of these treatments. The direct comparison of intra-arterial and intravenous thrombolytic drugs alone is the subject of another review (Wardlaw 2009).

The control (comparison therapy) was intravenous thrombolytic treatment, irrespective of dose or type of agent.

\section{Types of outcome measures}

\section{Primary outcomes}

Functional outcome at the end of the scheduled follow-up period, categorised by the modified Rankin Scale (mRS): good outcome: scores 0 to 2 (i.e. functional independence); poor outcome: scores 3 to 6 (i.e. functional dependency or death).

Given that some trials use the term 'favourable outcome', to denote mRS scores of 0 or 1 , we also sought data on the number of participants in each individual mRS category. If the mRS score was not reported, we used the trial's own definition of good or poor functional outcome.

\section{Secondary outcomes}

- Deaths from all causes, both:

* during the first two weeks, and

* at the end of the scheduled follow-up period.

- Symptomatic intracranial haemorrhage within the first two weeks and at the end of the follow-up period. We defined symptomatic intracranial haemorrhage according to the criteria that were used in the third European Cooperative Acute Stroke Study (ECASS III) (Hacke 2008). When symptomatic intracranial haemorrhages were not reported according to these criteria, we used the trial's definition.

- Vascular status, according to the Cerebral Infarction Perfusion Categories (Higashida 2003), and the Thrombolysis In Myocardial Infarction (TIMI) reperfusion score (Khatri 2005).

\section{Search methods for identification of studies}

See the 'Specialised register' section on the Cochrane Stroke website. We did not apply any language restrictions to our searches. We did not identify any relevant non-English-language papers when screening the abstracts and titles.

\section{Electronic searches}

We searched the Cochrane Stroke Trials Register, which was last searched by the Managing Editor in August 2018. In addition, we searched the following electronic databases.

- Cochrane Central Register of Controlled Trials (CENTRAL; 2017, Issue 9), in the Cochrane Library (Appendix 1);

- MEDLINE (from 1946 to September 2017) (Appendix 2);

- Embase (from 1980 to September 2017) (Appendix 3);

- Science Citation Index (from 1980 to September 2017);

- The following ongoing trials registers (last search: September 2017);

* Stroke Trials Registry (www.strokecenter.org/trials);

* US National Institutes of Health Ongoing Trials Register ClinicalTrials.gov (www.clinicaltrials.gov)

We developed the MEDLINE search strategy with the help of the Cochrane Stroke Information Specialist and adapted it for the other databases included in this review (Appendix 1; Appendix 2; Appendix 3).

\section{Searching other resources}

In an effort to identify further published, unpublished, ongoing and planned trials we:

- screened reference lists of relevant trials;

- contacted the manufacturers of any interventional radiological equipment included in the review;

- contacted professional societies in neuroradiology and interventional radiology;

- contacted authors and researchers active in the field;

- handsearched conference proceedings for the World Stroke Congress, International Stroke Congress, European Stroke Congress, the annual meeting of the European Society of Neuroradiology, and the annual meeting of the American Society of Neuroradiology.

\section{Data collection and analysis}

\section{Selection of studies}

One review author $(\mathrm{HL})$ screened titles and abstracts of references identified by the searches. We obtained full-paper copies of those trial reports that, from the title and abstract, appeared to be eligible for inclusion. Two review authors ( $\mathrm{HL}$ and $\mathrm{EB}$ ) then independently assessed these for inclusion. The review authors resolved any disagreements by discussion. When we excluded a trial we kept a record of both the report and the reason for exclusion.

\section{Data extraction and management}

Two review authors ( $\mathrm{HL}$ and $\mathrm{EB}$ ) independently extracted data from the report of each eligible trial on a specially designed data extraction form. The review authors were not blinded to journal or institution. We extracted the following data from each report:

- diagnostic criteria used for acute ischaemic stroke, including whether MRI diffusion and perfusion mismatch, CT angiography, or CT perfusion were used to identify eligible participants;

- location of the arterial occlusion;

- time interval from stroke onset to randomisation; 
- time to actual delivery of therapy/recanalisation, either percutaneous vascular or intravenous thrombolytic therapy (not start of procedure);

- numbers of participants in each treatment group with outcome events;

- modality of percutaneous vascular intervention used;

- agent and dose of pharmacological thrombolytic therapy used.

One review author $(\mathrm{HL})$ entered the data into Review Manager 5 (RevMan 5) software (Review Manager 2014). Another review author (EB), checked these data against the data extraction forms to correct any clerical data entry errors. When any relevant data were missing from the available publications, we contacted the principal investigators or sponsors concerned.

\section{Assessment of risk of bias in included studies}

Two of the review authors ( $\mathrm{HL}$ and $\mathrm{EB}$ ) independently assessed risk of bias for each included study. We appraised selection bias by assessing the random sequence generation and allocation concealment of the intervention. We appraised performance and detection bias by assessing the blinding of participants, personnel, and outcome assessors. We appraised attrition bias by checking the number of participants lost to follow-up and participants excluded from the study, and appraised any reporting or other biases in the studies. We scored these data as low risk of bias, unclear risk, or high risk of bias.

Two review authors ( $\mathrm{HL}$ and $\mathrm{EB}$ ) independently performed quality assessment of reports of eligible trials; they resolved any disagreements by discussion. We used the following criteria to assess the quality of reports of eligible trials according to section 8.5.3 of the Cochrane Handbook for Systematic Reviews of Interventions (Higgins 2017):

- adequate sequence generation;

- allocation concealment;

- blinding: in trials of percutaneous vascular interventions it is not possible to blind the participants or those providing the interventions. In this review, we categorised trials as 'blinded' if outcome assessors were blinded to the treatment that the participant had received;

- incomplete outcome data addressed: we considered intentionto-treat analysis (ITT) adequate when:

* participants were analysed in the groups to which they had been randomised, regardless of what treatment they received, and

* when the numbers of participants lost to follow-up and the associated reasons were reported

- no selective reporting;

- no other bias.

We used the above criteria to construct a 'Risk of bias' table for each eligible trial, as outlined in section 8.6 of the Cochrane Handbook for Systematic Reviews of Interventions (Higgins 2017).

\section{Measures of treatment effect}

For dichotomous outcomes, we calculated a weighted estimate of the treatment effects across trials and reported risk ratios (RR) with 95\% confidence intervals (CI). For studies that used scales for the assessment of similar outcomes, we reported mean differences (MD).

\section{Dealing with missing data}

If the published information did not allow intention-to-treat analysis, we planned to contact the authors to get as complete follow-up data as possible on all randomised participants for the originally proposed period of follow-up. If the data for these participants remained unavailable, we planned to provide a worstcase scenario analysis for the composite outcome of 'death and severe disability'. In this sensitivity analysis, we would assume that those participants who were lost to follow-up in the treatment group had the worst outcome while those participants who were lost to follow-up in the control group had the best outcome.

However, this was not done as no participants were lost to followup in any of the studies.

\section{Assessment of heterogeneity}

We used $\mathrm{Chi}^{2}$ statistic and $\mathrm{I}^{2}$ statistic (percentage of total variation across studies due to heterogeneity) to test for heterogeneity between trial results. We also assessed heterogeneity qualitatively (Deeks 2017).

\section{Assessment of reporting biases}

We planned to use funnel plots to assess reporting bias and to assess funnel plots qualitatively. This was not done as we did not identify enough trials to assess reporting bias by funnel plots (Sterne 2017).

\section{Data synthesis}

We calculated a weighted estimate of the typical treatment effect across trials by means of a fixed-effect model. In the case of heterogeneity of treatment effects, we planned to use the randomeffects model to assess the overall treatment effects.

\section{GRADE and 'Summary of findings' table}

We used GRADE to assess the quality of evidence for the outcomes (Schünemann 2013). Two review authors (HL and EB) independently assessed the quality of evidence for each outcome. We considered RCTs as high quality but downgraded evidence based on the following.

- Limitations in the design and implementation of available studies suggesting high likelihood of bias.

- Indirectness of evidence (indirect population, intervention, control, outcomes).

- Unexplained heterogeneity or inconsistency of results (including problems with subgroup analyses).

- Imprecision of results (wide confidence intervals).

- High probability of publication bias.

We used the GRADEPro Guideline Development Tool to create Summary of findings for the main comparison and to report the quality of the evidence (GRADEpro GDT 2015).

The GRADE approach specifies four levels of quality:

- High: we are very confident that the true effect lies close to the estimate of effect. 
- Moderate: we are moderately confident in the effect estimate: the true effect is likely to be close to the estimate of effect but may be substantially different.

- Low: our confidence in the effect estimate is limited: the true effect may be substantially different from the estimate of effect.

- Very low: we have very little confidence in the effect estimate: the true effect is likely to be substantially different from the estimate of effect.

\section{Subgroup analysis and investigation of heterogeneity}

We planned to do subgroup analyses for concomitant antithrombotic therapy, stroke severity, time since stroke symptom onset (that is, symptom onset), modality of the percutaneous vascular intervention, dose and type of agent used for intravenous thrombolytic treatment, and anatomy of the arterial occlusion. However, we did not identify enough trials to do subgroup analyses.

\section{RESULTS}

\section{Description of studies}

See Characteristics of included studies; Characteristics of excluded studies; Characteristics of ongoing studies.

\section{Results of the search}

The searches of MEDLINE and Embase identified 2687 and 6218 citations. We removed 1068 duplicates, leaving 7837 citations for review of title and abstract. The search of CENTRAL identified 790 citations. Searches of Cochrane Stroke Group Trials Register and Science Citation Index and reviewing the reference lists of included studies did not identify any additional studies. We contacted researchers active in the field, professional organisations and manufacturers of interventional radiological equipment and received replies from Joseph Broderlick, Takashi Inoue, Keith Muir, Wouter Schonewille, Michael Söderman, and Phil White, British Society of Neuroradiologists, and Penumbra Inc. This did not identify additional studies.

After reviewing the titles and abstracts, we retrieved full texts for seven studies. We excluded three studies because the control group did not receive intravenous thrombolytic medication (Del Zoppo 1998; Furlan 1999; Ogawa 2007). We identified one ongoing study after searching Stroke Trials Registry, ClinicalTrials.gov, and Current Controlled Trials (NCT01455935). We included four studies (Ducrocq 2005; Sen 2009; SYNTHESIS Expansion 2013; SYNTHESIS Pilot 2010).

Figure 1 shows the PRISMA flow diagram of the study selection process. 
Figure 1. Study flow diagram

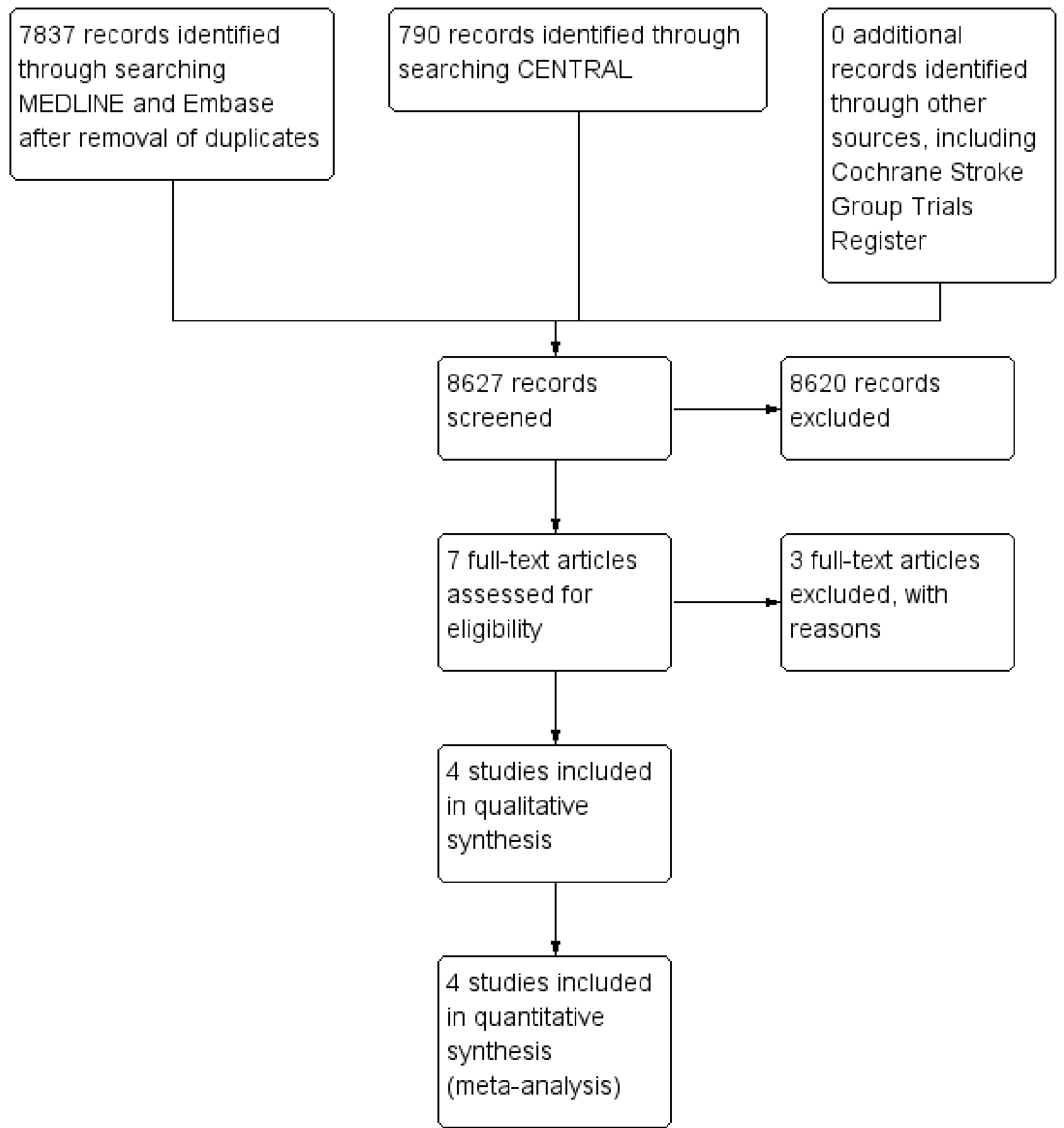

\section{Included studies}

We identified four trials with 450 participants randomised to percutaneous vascular interventions or intravenous thrombolysis (Ducrocq 2005; Sen 2009; SYNTHESIS Pilot 2010; SYNTHESIS Expansion 2013).

\section{Angiographic diagnostic criteria and topography of strokes included}

Three trials did not select participants based on location of the arterial occlusion (Ducrocq 2005; SYNTHESIS Expansion
2013; SYNTHESIS Pilot 2010). One trial included participants with proximal occlusion strokes in either the middle cerebral (M1 or M2), terminal internal carotid, basilar, or vertebral artery using computed tomography angiography (Sen 2009). See Characteristics of included studies.

In Ducrocq 2005, all 13 participants in the intervention group had an occlusion in the middle cerebral artery trunk. Angiography was not performed in the controls. Of the seven participants included in Sen 2009, six had an occlusion in the middle cerebral artery and one had an occlusion in the internal carotid artery. In SYNTHESIS Pilot 
2010, 20 participants in the intervention group had an occlusion in the anterior circulation, four in the posterior circulation, and one had an undefined location of stroke. In the control group, 27 participants had an occlusion in the anterior circulation, one participant in the posterior circulation, and one had an undefined location of stroke. In SYNTHESIS Expansion 2013, 160 participants had an occlusion in the anterior circulation, 18 participants in the posterior circulation, and one participant in both the anterior and posterior circulation. In the control group, 170 participants had an occlusion in the anterior circulation and 11 participants in the posterior circulation.

\section{Age and gender of included participants}

The mean age of the participants in the intervention group in Ducrocq 2005 was 60 years and in the control group 58 years. The mean age of all seven participants in Sen 2009 was 68 years. The mean age of participants in the intervention group in SYNTHESIS Pilot 2010 was 61 years and in the control group 64 years. The mean age of participants in the intervention group in SYNTHESIS Expansion 2013 was 66 years and in the control group 67 years.

Three studies specified the number of men and women in the study groups (Ducrocq 2005; SYNTHESIS Expansion 2013; SYNTHESIS Pilot 2010). Across these studies, 137 (63\%) of 219 participants randomised to the intervention group and $135(60 \%)$ of 224 participants randomised to the control group were men. More men than women were randomised to the intervention group in Ducrocq 2005 (12 out of 13 in the intervention group versus 9 out of 14 in the control group). There were no gender differences in SYNTHESIS Expansion 2013 and SYNTHESIS Pilot 2010.

\section{Medical history}

In Ducrocq 2005, the study groups were balanced with respect to the proportion of participants with hypertension, diabetes, atrial fibrillation, and dyslipidaemia. In SYNTHESIS Expansion 2013, the study groups were balanced with respect to use of antihypertensive, antidiabetes, and antiplatelet therapy. However, the proportion of participants with atrial fibrillation was larger in the control group than in the intervention group (16\% versus $8 \%$ ). There was little information about background medical history in Sen 2009 and SYNTHESIS Pilot 2010.

\section{Time interval from stroke onset to randomisation and start of procedure}

Ducrocq 2005 included participants with initiation of treatment within six hours after stroke onset. Sen 2009 included participants randomised within three hours after stroke onset. SYNTHESIS Pilot 2010 included participants with initiation of treatment within three hours after stroke onset (treatment in the intervention group was allowed up to six hours after stroke onset). SYNTHESIS Expansion 2013 included participants with initiation of treatment within 4.5 hours after stroke onset.

Median time from stroke onset to start of treatment in the intervention group

\begin{tabular}{lll}
\hline & Intervention group & Control group \\
\hline Ducrocq 2005 & $5: 24$ hours & $4: 16$ hours \\
\hline Sen 2009 & Not reported & Not reported \\
\hline SYNTHESIS Pilot 2010 & $3: 45$ hours & $2: 45$ hours \\
\hline SYNTHESIS Expansion 2013 & $3: 15$ hours & $2: 35$ hours \\
\hline
\end{tabular}

Only one trial had data on the time interval from stroke onset to randomisation (SYNTHESIS Expansion 2013). This was 2:28 hours for the intervention group and 2:25 hours for the control group

Drug usage, and means of drug delivery

\begin{tabular}{|c|c|c|c|c|}
\hline & Ducrocq 2005 & Sen 2009 & SYNTHESIS Pilot 2010 & SYNTHESIS Expansion 2013 \\
\hline \multirow[t]{3}{*}{$\begin{array}{l}\text { Intervention } \\
\text { group }\end{array}$} & $\begin{array}{l}\text { Intra-arterial } \\
\text { urokinase }\end{array}$ & Intra-arterial rt-PA, & Intra-arterial rt-PA & Intra-arterial rt-PA \\
\hline & & maximum 20 mg & 0.9 mg per kg (maximum 90 & $0.9 \mathrm{mg}$ per kg (maximum 90 \\
\hline & 900,000 units & & $\mathrm{mg})$ & $\mathrm{mg})$ \\
\hline \multirow[t]{4}{*}{ Control group } & Intravenous & Intravenous rt-PA & Intravenous rt-PA & Intravenous rt-PA \\
\hline & & $0.9 \mathrm{mg}$ per $\mathrm{kg}$ (maximum & $0.9 \mathrm{mg}$ per kg (maximum 90 & $0.9 \mathrm{mg}$ per kg (maximum 90 \\
\hline & 900,000 units & $90 \mathrm{mg})$ & $\mathrm{mg})$ & $\mathrm{mg})$ \\
\hline & & $\begin{array}{l}10 \% \text { given as a bolus } \\
\text { dose, }\end{array}$ & $10 \%$ given as a bolus dose, & $10 \%$ given as a bolus dose, \\
\hline
\end{tabular}


Modality of percutaneous vascular intervention used in the intervention groups

\begin{tabular}{|c|c|c|c|c|c|}
\hline & Total & Ducrocq 2005 & Sen 2009 & $\begin{array}{l}\text { SYNTHESIS } \\
\text { Expansion } \\
2013\end{array}$ & $\begin{array}{l}\text { SYNTHESIS Pi- } \\
\text { lot } 2010\end{array}$ \\
\hline $\begin{array}{l}\text { Manipulation of microcatheter tip plus in- } \\
\text { tra-arterial thrombolysis }\end{array}$ & $132(59 \%)$ & 13 & 3 & 109 & 7 \\
\hline $\begin{array}{l}\text { Use of devicea in addition to manipula- } \\
\text { tion of microcatheter tip plus intra-arterial } \\
\text { thrombolysis }\end{array}$ & $58(26 \%)$ & 0 & 0 & 56 & 2 \\
\hline $\begin{array}{l}\text { Only intra-arterial thrombolysis (no me- } \\
\text { chanical manoeuvre) }\end{array}$ & $10(5 \%)$ & 0 & 0 & 0 & 10 \\
\hline No intervention ${ }^{b}$ & $22(10 \%)$ & 0 & 0 & 16 & 6 \\
\hline
\end{tabular}

aSYNTHESIS Pilot 2010: goose-neck microsnare $(n=1)$ and carotid stent $(n=1)$. SYNTHESIS Expansion 2013: Solitaire stent $(n=$ 18), Trevo stent $(n=5)$, Merci thrombus retriever device $(n=5)$, Penumbra thromboaspiration device $(n=9)$, balloon alone $(n=5)$, and other stents or retrievers $(n=19)$. In this trial some participants were treated with more than one device, so the total number of devices is higher than 56.

bIn SYNTHESIS Pilot 2010: because of no artery occlusion on angiogram $(n=6)$. In SYNTHESIS Expansion 2013: because of clinical improvement $(n=6)$, no artery occlusion on angiogram ( $n$ $=3)$, dissection ( $n=3)$, unknown bleeding diathesis $(n=1)$, groin haematoma $(n=1)$, delayed availability of interventionist $(n=1)$, and equipment breakdown $(n=1)$.

\section{Concomitant use of antithrombotic treatment}

\section{Intervention group}

\begin{tabular}{ll}
\hline Ducrocq 2005 & Unfractionated heparin: 1000 units (bolus) plus 1000 units per hour as infusion \\
\hline Sen 2009 & Unfractionated heparin: 120 units per hour as infusion \\
\hline SYNTHESIS Expansion 2013 & Unfractionated heparin: 5000 units (bolus) plus 500 units per hour as infusion \\
\hline SYNTHESIS Pilot 2010 & Unfractionated heparin: 2000 units (bolus) plus 500 units per hour as infusion \\
\hline
\end{tabular}

\section{Assessment of outcome}

Three trials reported functional outcome at end of follow-up according to the mRS score (Ducrocq 2005; SYNTHESIS Expansion 2013; SYNTHESIS Pilot 2010). Three trials reported mortality at the end of follow-up (Ducrocq 2005; SYNTHESIS Expansion 2013; SYNTHESIS Pilot 2010). One trial was a feasibility study that did not report functional outcome or death (Sen 2009). All included trials reported symptomatic intracranial haemorrhage within 14 days.
Only one trial reported recanalisation rates according to the $\mathrm{TICl}$ classification (Sen 2009). See Characteristics of included studies.

\section{Excluded studies}

We excluded three studies (Del Zoppo 1998; Furlan 1999; Ogawa 2007).

\section{Risk of bias in included studies}

See Included studies, Figure 2 and Figure 3. 
Figure 2. 'Risk of bias' graph: review authors' judgements about each risk of bias item presented as percentages across all included studies

Random sequence generation (selection bias)

Allocation concealment (selection bias)

Blinding of participants and personnel (performance bias)

Blinding of outcome assessment (detection bias)

Incomplete outcome data (attrition bias)

Selective reporting (reporting bias)

Other bias
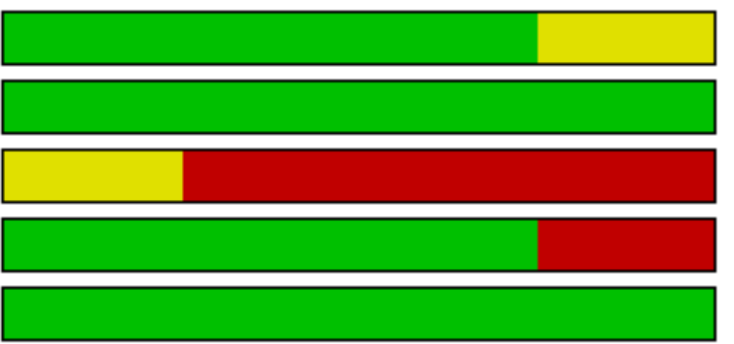

$$
\text { L }
$$

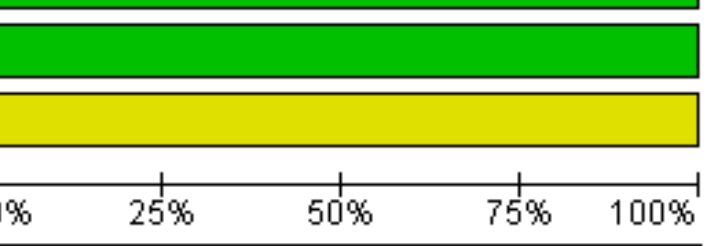


Figure 3. 'Risk of bias' summary: review authors' judgements about each risk of bias item for each included study

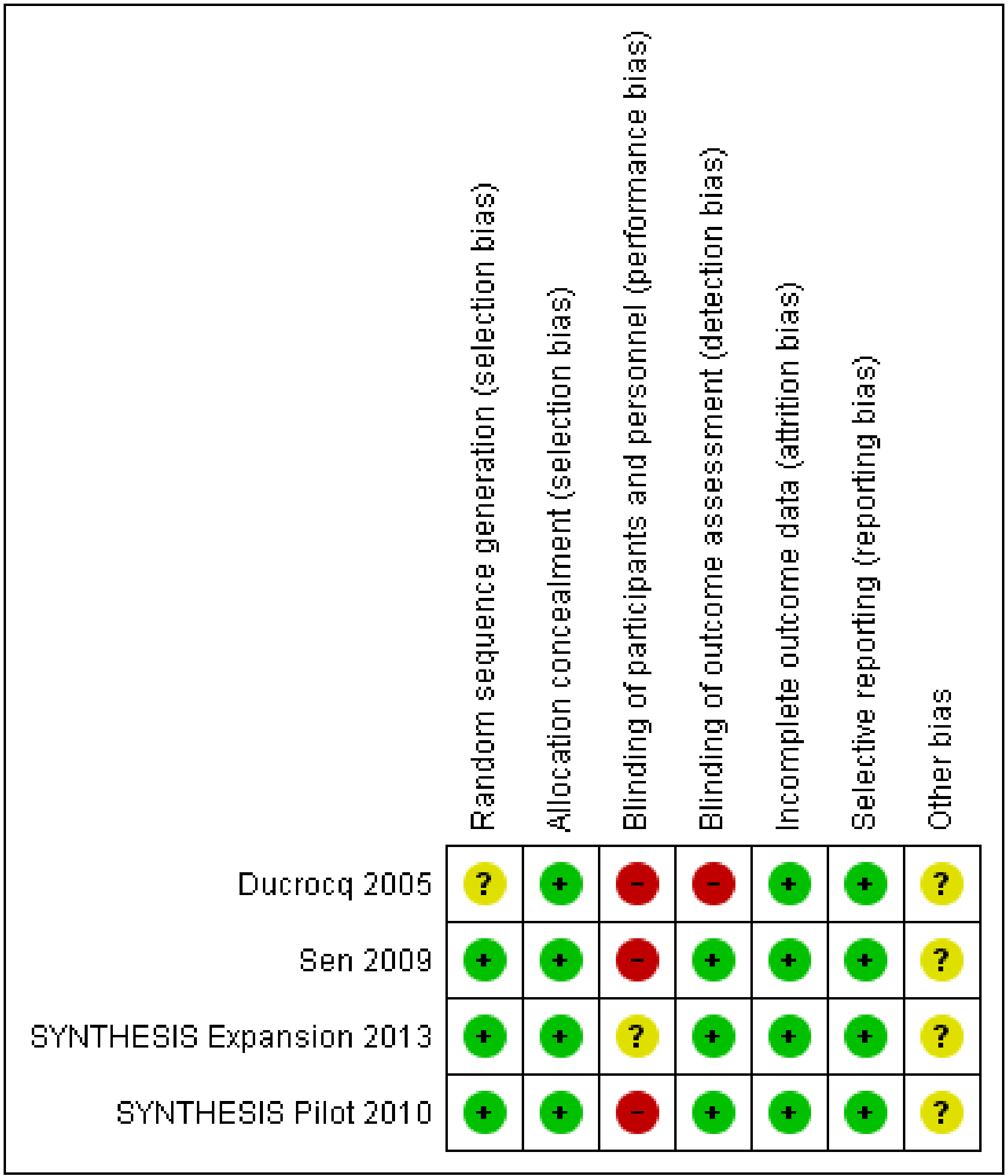

\section{Allocation}

Allocation bias was low in Sen 2009; SYNTHESIS Expansion 2013 and SYNTHESIS Pilot 2010, which used computer-generated random number generators. The risk of bias was unclear in Ducrocq 2005 as they did not describe the randomisation procedure.

\section{Blinding}

All studies were at high risk of performance bias as participants and personnel were not blinded to treatment allocation.

There was low risk of detection bias in three studies where outcome assessors were blinded to treatment allocation (Sen 2009; 
SYNTHESIS Expansion 2013; SYNTHESIS Pilot 2010). One trial had high risk of detection bias as the outcome assessor was not blinded to treatment allocation (Ducrocq 2005).

\section{Incomplete outcome data}

We considered the completeness of outcome data to be at low risk of bias for all included trials as no participants were lost to followup in any of the included trials.

\section{Selective reporting}

All trials were at low risk of bias as no participants were lost to follow-up.

\section{Other potential sources of bias}

One trial had a high risk of bias as it was terminated early due to high case fatality and suffered from a lack of statistical power (Ducrocq 2005).

\section{Effects of interventions}

See: Summary of findings for the main comparison Percutaneous vascular interventions compared to intravenous thrombolytic treatment for acute ischaemic stroke

See Summary of findings for the main comparison for the main comparison.

\section{Functional outcome at the end of follow-up}

The number of participants with a mRS score 0 to 2 at the end of follow-up was available for a total of 443 participants from three trials (Ducrocq 2005; SYNTHESIS Expansion 2013; SYNTHESIS Pilot 2010). Sen 2009 was a feasibility study of only seven participants and did not provide data on outcome. There was no evidence of an effect of the intervention on the proportion of participants with mRS scores of 0 to 2 (RR $1.01,95 \% \mathrm{Cl} 0.82$ to $1.25, \mathrm{P}=0.92$ ), with no significant between-study heterogeneity $\left(\mathrm{I}^{2}=58 \%, \mathrm{P}=0.09\right.$; Analysis 1.1).

The number of participants in each mRS category was available for a total of 443 participants from the same trials (Ducrocq 2005; SYNTHESIS Expansion 2013; SYNTHESIS Pilot 2010).

Participants in the intervention group had a statistically significant improvement in the mean mRS score (MD $-0.43,95 \% \mathrm{Cl}-0.81$ to $-0.04, P=0.03)$, with no significant between-study heterogeneity $(12$ $=0 \%, \mathrm{P}=0.40$; Analysis 1.2).

Quality of evidence was low (outcome assessment was blinded, but not treating physician or participants).

\section{Death from all causes}

Data on death at the end of follow-up were available for a total of 443 participants from three trials (Ducrocq 2005; SYNTHESIS Expansion 2013; SYNTHESIS Pilot 2010). At the end of followup, there was a non-significant increase in the proportion of participants who died in the intervention group (RR 1.34, 95\% $\mathrm{Cl} 0.84$ to $2.14, \mathrm{P}=0.21$ ), with no significant between-study heterogeneity $(12=0 \%, P=0.72$; Analysis 1.3$)$.

Data on death within 14 days were available for a total of 416 participants from two trials (SYNTHESIS Expansion 2013; SYNTHESIS Pilot 2010). At the end of follow-up, there was a non- significant increase in the proportion of participants who died in the intervention group ( $\mathrm{RR} 1.32,95 \% \mathrm{Cl} 0.69$ to $2.51, \mathrm{P}=0.40$ ), with no significant between-study heterogeneity $(12=0 \%, P=0.86$; Analysis 1.4).

Quality of evidence was low (wide confidence interval).

\section{Symptomatic intracranial haemorrhage}

Data on symptomatic intracranial haemorrhages within first 14 days were available for a total of 450 participants from four trials (Ducrocq 2005; Sen 2009; SYNTHESIS Expansion 2013; SYNTHESIS Pilot 2010). There was no difference in the proportion of participants with symptomatic intracranial haemorrhages between the intervention and control groups (RR $0.99,95 \% \mathrm{Cl} 0.50$ to $1.95, \mathrm{P}$ $=0.97)$, with no significant between-study heterogeneity $\left(I^{2}=0 \%, P\right.$ $=0.57$; Analysis 1.5 ).

Quality of evidence was low (wide confidence interval).

\section{Vascular status (recanalisation rate)}

Data on vascular status (recanalisation rate) of the occluded artery were available for a total of seven participants in one trial (Sen 2009). We considered the sample size inadequate for statistical analyses.

\section{Subgroup analyses and sensitivity analyses}

There were not enough data to perform subgroup or sensitivity analyses.

\section{DISCUSSION}

\section{Summary of main results}

The present review directly compared intravenous thrombolytic treatment with percutaneous vascular interventions for ischaemic stroke. We found no difference in the proportion of participants with good functional outcome at end of follow-up and no statistically significant differences in the risk of death or intracranial haemorrhage.

Although there was no difference in the proportion of participants with good outcome (mRS score 0 to 2 ), we found that percutaneous vascular interventions slightly improved the mean mRS score at follow-up compared with intravenous thrombolytic treatment. This should be interpreted with caution as the finding was not very robust and a change in mean mRS score does not describe a clinically meaningful effect.

\section{Overall completeness and applicability of evidence}

Evaluating the clinical benefit of a change in the mean mRS score difference is difficult. The mRS is a non-linear scale, and a 1point transition from 6 to 5 qualitatively differs from a 1-pont transition from 1 to 0 . Dichotomous analyses of the transition from independence to dependency (mRS score 0 to 2 versus 3 to 6 ) may be more appropriate, although this approach does not value other clinically important transitions (such as a transition from severe dependency (mRS score 5) to the ability to walk without assistance (score 3; Saver 2007). Further, this approach reduces statistical power as participants at one end of the spectrum are less likely to cross the binary threshold and contribute data to the analysis (Berge 2002). 
A major limitation of the study is the limited number of included trials. This resulted in wide confidence intervals. Further, the tests of heterogeneity when based on a limited number of studies, as it is the case in this review, has a very low power and does not provide reliable results. Substantial heterogeneity is likely present despite the tests being non-significant.

Several recent thrombectomy trials have been published (DAWN 2018; DEFUSE 3 2018; EXTEND-IA 2015; IMS III 2013; MR CLEAN 2015; MR RESCUE 2013; REVASCAT 2015; SWIFT PRIME 2015). A majority of these trials showed benefit of percutaneous vascular interventions compared with no such therapy. However, we did not include these trials in the present meta-analysis because they did not compare directly percutaneous vascular interventions and intravenous thrombolytic therapies.

Percutaneous vascular interventions are associated with improved arterial recanalisation compared with intravenous thrombolytic treatment (Baker 2011; Goyal 2015). However, our review did not find that this translated into improved clinical outcome compared with intravenous thrombolytic treatment. The cause for this is unknown. One possible explanation is that it takes more time to initiate percutaneous vascular interventions compared with intravenous thrombolytic treatment.

\section{Quality of the evidence}

The quality was low, with high risk of bias due to participants and treating physicians not blinded in the trials.

\section{Potential biases in the review process}

There is always a risk of publication bias with systematic reviews; however, we tried to avoid this by using a very comprehensive search strategy and including published and unpublished studies.

\section{Agreements and disagreements with other studies or reviews}

There is a rapid development of new percutaneous vascular interventions. Only a minority of the participants from the included studies were treated with (mostly first-generation) intra-arterial devices. The new stent retrievers have been shown to improve time to recanalisation and clinical outcome compared with the first-generation devices (Nogueira 2012; Saver 2012), and may improve clinical outcome compared with intravenous thrombolytic treatment.

Unfortunately, we were not able to include these more recent trials as none of them randomised participants to intravenous versus percutaneous therapy. Instead, all trials randomised participants to intravenous versus intravenous plus percutaneous therapy or best medical care versus best medical care plus percutaneous therapy. Caution is warranted in forgoing intravenous thrombolytic treatment in people with ischaemic stroke who are eligible for both treatments, especially if this delays time to recanalisation. However, a post-hoc analysis of pooled data from two trials of a percutaneous vascular intervention (Solitaire with the intention for thrombectomy and Solitaire flow restoration thrombectomy for acute revascularisation) found similar outcomes in subgroups of participants who were given intravenous thrombolytic treatment before percutaneous vascular intervention compared with participants who were only treated with a percutaneous vascular intervention (Coutinho 2017). However, post-hoc analyses should be interpreted with caution due to the risk of spurious findings, and a trial of forgoing intravenous thrombolytic treatment in participants with ischaemic stroke that can be given both treatments is warranted.

\section{AUTHORS' CONCLUSIONS}

\section{Implications for practice}

There was no evidence from the randomised controlled trials that directly compared percutaneous vascular interventions with intravenous thrombolytic treatment that showed that percutaneous vascular interventions were superior.

\section{Implications for research}

New trials should be of sufficient size, and should employ the latest generation devices. There may not be much equipoise among the clinical research community regarding the benefit of percutaneous interventions in proximal occlusion strokes. Future trials may, therefore, focus on people with mild-to-moderate strokes and on whether it is safe to forgo intravenous thrombolytic treatment in people with ischaemic stroke who are eligible for both treatments.

\section{ACKN OWLEDGEMENTS}

We thank Brenda Thomas for her help in developing the search strategies.

We thank Xavier Ducrocq and Serge Bracard for providing additional unpublished data from Ducrocq 2005. We thank Alfonso Ciccone for providing additional unpublished data from SYNTHESIS Expansion 2013 and SYNTHESIS Pilot 2010.

We thank Joseph Broderlick, Takashi Inoue, Keith Muir, Wouter Schonewille, Michael Söderman, and Phil White, British Society of Neuroradiologists, and Penumbra Inc for responding to our request for information about completed, ongoing, and planned studies. 


\section{R E F E R E N C E S}

\section{References to studies included in this review}

Ducrocq 2005 \{published and unpublished data\}

Ducrocq X, Bracard S, Taillandier L, Anxionnat R, Lacour JC, Guillemin F, et al. Comparison of intravenous and intra-arterial urokinase thrombolysis for acute ischaemic stroke. Journal of Neuroradiology 2005;32:26-32.

Sen 2009 \{published data only (unpublished sought but not used)\} Sen S, Huang DY, Akhavan O, Wilson S, Verro P, Solander S. IV vs. IA TPA in acute ischemic stroke with CT angiographic evidence of major vessel occlusion: a feasibility study. Neurocritical Care 2009;11:76-81.

\section{SYNTHESIS Expansion 2013 \{published and unpublished data\}}

Ciccone A, Valvassori L, Nichelatti M, Sgoifo A, Ponzio M, Sterzi R, et al. Endovascular treatment for acute ischemic stroke. New England Journal of Medicine 2013;368:904-13.

\section{SYNTHESIS Pilot 2010 \{published and unpublished data\}}

Ciccone A, Valvassori L, Ponzio M, Ballabio M, Gasparotti R, Sessa M, et al. Intra-arterial or intravenous thrombolysis for acute ischemic stroke? The SYNTHESIS pilot trial. Journal of Neurointerventional Surgery 2010;2:74-9.

\section{References to studies excluded from this review \\ Del Zoppo 1998 \{published data only\}}

Del Zoppo GJ, Higashida RT, Furlan AJ, Pessin MS, Rowley HA, Gent M. PROACT: a phase II randomized trial of recombinant pro-urokinase by direct arterial delivery in acute middle cerebral artery stroke. Stroke 1998;29:4-11.

\section{Furlan 1999 \{published data only\}}

Furlan A, Higashida R, Wechsler L, Gent M, Rowley H, Kase C, et al. Intra-arterial prourokinase for acute ischemic stroke. The PROACT II Study: a randomized controlled trial. JAMA 1999;282:2003-11.

\section{Ogawa 2007 \{published data only\}}

Ogawa A, Mori E, Minematsu K, Taki W, Takahashi A, Nemoto S, et al. Randomized trial of intraarterial infusion of urokinase within 6 hours of middle cerebral artery stroke: the Middle Cerebral Artery Embolism Local Fibrinolytic Intervention Trial (MELT) Japan. Stroke 2007;38:2633-9.

\section{References to ongoing studies}

NCT01455935 \{published data only\}

NCT01455935. Wake up symptomatic stroke - benefit of intravenous clot busters or endovascular intervention (WASSABI). clinicaltrials.gov/ct2/show/NCT01455935 (first received 1 September 2017).

\section{Additional references}

\section{Adams 2007}

Adams HP Jr, del Zoppo G, Alberts MJ, Bhatt DL, Brass L, Furlan $A$, et al. Guidelines for the early management of adults with ischemic stroke: a guideline from the American Heart Association/American Stroke Association Stroke Council, Clinical Cardiology Council, Cardiovascular Radiology and Intervention Council, and the Atherosclerotic Peripheral Vascular Disease and Quality of Care Outcomes in Research Interdisciplinary Working Groups. Stroke 2007;38:1655-711.

\section{Baker 2011}

Baker WL, Colby JA, Tongbram V, Talati R, Silverman IE, White M, et al. Neurothrombectomy devices for the treatment of acute ischemic stroke: state of the evidence. Annals of Internal Medicine 2011;154:243-52.

\section{Berge 2002}

Berge E, Barer D. Could stroke trials be missing important treatment effects?. Cerebrovascular Diseases 2002;13:73-5.

\section{Coutinho 2017}

Coutinho JM, Liebeskind DS, Slater LA, Nogueira RG, Clark W, Dávalos A, et al. Combined intravenous thrombolysis and thrombectomy vs thrombectomy alone for acute ischemic stroke: a pooled analysis of the SWIFT and STAR studies. JAMA Neurology 2017;74:268-74.

\section{DAWN 2018}

Nogueira PG, Jadhav AP, Haussen DC, Bonafe A, Budzik RF, Bhuva P, et al. Thrombectomy 6 to 24 hours after stroke with a mismatch between deficit and infarct. New England Journal of Medicine 2018;378:11-21.

\section{Deeks 2017}

Deeks JJ, Higgins JP, Altman DG (editors) on behalf ofthe Cochrane Statistical Methods Group. Chapter 9: Analysing data and undertaking meta-analyses. In: Higgins JPT, Churchill R, Chandler J, Cumpston MS (editors), Cochrane Handbook for Systematic Reviews of Interventions version 5.2.0 (updated June 2017), Cochrane, 2017. Available from www.training.cochrane.org/handbook.

\section{DEFUSE 32018}

Albers GW, Marks MP, Kemp S, Christensen S, Tsai JP, OrtegaGutierrez S, et al. Thrombectomy for stroke at 6 to 16 hours with selection by perfusion imaging. New England Journal of Medicine 2018;378:708-18.

\section{Del Zoppo 2009}

Del Zoppo GJ, Saver JL, Jauch EC, Adams HP Jr, the American Heart Association/American Stroke Association. Expansion of the time window for treatment of acute ischemic stroke with intravenous tissue plasminogen activator: a science advisory from the American Heart Association/American Stroke Association. Stroke 2009;40:2945-8. 


\section{Emberson 2014}

Emberson J, Lees KR, Lyden P, Blackwell L, Albers G, Bluhmki E, et al. Effect of treatment delay, age, and stroke severity on the effects of intravenous thrombolysis with alteplase for acute ischaemic stroke: a meta-analysis of individual patient data from randomised trials. Lancet 2014;28(384):1929-35.

\section{ESO 2009}

European Stroke Organisation. Guidelines for management of ischaemic stroke and transient ischaemic attack 2008 (updated January 2009). www.eso-stroke.org/recommendations.php? cid $=9$.

\section{EXTEND-IA 2015}

Campbell BC, Mitchell PJ, Kleinig TJ, Dewey HM, Churilov L, Yassi N, the EXTEND-IA Investigators. Endovascular therapy for ischemic stroke with perfusion-imaging selection. New England Journal of Medicine 2015;372:1009-18.

\section{Goyal 2015}

Goyal M, Demchuk AM, Menon BK, Eesa M, Rempel JL, Thornton J, the ESCAPE Trial Investigators. Randomized assessment of rapid endovascular treatment of ischemic stroke. New England Journal of Medicine 2015;372:1019-30.

\section{GRADEpro GDT 2015 [Computer program]}

McMaster University (developed by Evidence Prime). GRADEpro GDT. Version - date accessed 24 September 2018. Hamilton (ON): McMaster University (developed by Evidence Prime), 2015.

\section{Hacke 2008}

Hacke W, Kaste M, Bluhmki E, Brozman M, Dávalos A, Guidetti D, et al. Thrombolysis with alteplase 3 to 4.5 hours after acute ischemic stroke. New England Journal of Medicine 2008;359:1317-29.

\section{Higashida 2003}

Higashida R, Furlan A, Roberts H, Tomsick T, Connors B, Barr J, et al. Trial design and reporting standards for intraarterial cerebral thrombolysis for acute ischemic stroke. Stroke 2003;34:e109-37.

\section{Higgins 2017}

Higgins JP, Altman DG, Sterne JA (editors). Chapter 8: Assessing risk of bias in included studies. In: Higgins JPT, Churchill R, Chandler J, Cumpston MS (editors), Cochrane Handbook for Systematic Reviews of Interventions version 5.2.0 (updated June 2017), Cochrane, 2017. Available from www.training.cochrane.org/handbook.

\section{IMS III 2013}

Broderick JP, Palesh YY, Demchuk AM, Yeatts SD, Kathri P, Hill MD, et al. Endovascular therapy after Intravenous t-PA versus t-PA alone for stroke. New England Journal of Medicine 2013;368(10):893-903.

\section{Khatri 2005}

Khatri P, Neff J, Broderick J, Khoury J, Carrozzella J, Tomsick T, et al. Revascularization end points in stroke interventional trials: recanalization versus reperfusion in IMS-I. Stroke 2005;36:2400-3.

\section{Menon 2015}

Menon BK, Saver JL, Goyal M, Nogueira R, Prabhakaran S, Liang L, et al. Trends in endovascular therapy and clinical outcomes within the nationwide Get With The GuidelinesStroke registry. Stroke 2015;46(4):989-95.

\section{MR CLEAN 2015}

Berkhemer OA, Fransen PSS, Beumer D, Van den Berg LA, Lingsma HF, Yoo AJ, the MR CLEAN Investigators. A randomized trial of intraarterial treatment for acute ischemic stroke. New England Journal of Medicine 2015;371:11-20.

\section{MR RESCUE 2013}

Kidwell CS, Jahan R, Gornbein J, Alger JR, Nenov V, Ajani Z, the MR RESCUE Investigators. A trial of imaging selection and endovascular treatment for ischemic stroke. New England Journal of Medicine 2013;368:914-23.

\section{Nogueira 2012}

Nogueira RG, Lutsep HL, Gupta R, Jovin TG, Albers GW, Walker GA, et al. Trevo versus Merci retrievers for thrombectomy revascularisation of large vessel occlusions in acute ischaemic stroke (TREVO 2): a randomised trial. Lancet 2012;380:1231-40.

\section{REVASCAT 2015}

Jovin TG, Chamorro A, Cobo E, de Miquel MA, Molina CA, Rovira A, the REVASCAT Trial Investigators. Thrombectomy within 8 hours after symptom onset in ischemic stroke. New England Journal of Medicine 2015;372:2296-306.

\section{Review Manager 2014 [Computer program]}

Nordic Cochrane Centre: The Cochrane Collaboration. Review Manager 5 (RevMan 5). Version 5.3. Copenhagen: Nordic Cochrane Centre: The Cochrane Collaboration, 2014.

\section{Rosamund 2008}

Rosamund W, Flegal K, Furie K, Go A, Greenlund K, Haase N, et al. Heart disease and stroke statistics: 2008 update - a report from the American Heart Association Statistics Committee and Stroke Statistics Subcommittee. Circulation 2008;117:e25-146.

\section{Saver 2007}

Saver JL. Novel end point analytic techniques and interpreting shifts across the entire range of outcome scales in acute stroke trials. Stroke 2007;38:3055-62.

\section{Saver 2012}

Saver JL, Jahan R, Levy El, Baxter B, Nogueira RG, Clark W, et al. Solitaire flow restoration device versus the Merci retriever in patients with acute ischaemic stroke (SWIFT): a randomised, parallel-group, non-inferiority trial. Lancet 2012;380:1241-49.

\section{Schünemann 2013}

Schünemann H, Brożek J, Guyatt G, Oxman A (editors) GRADE Working Group. GRADE Handbook. Handbook for grading quality of evidence and strength of recommendations. www.guidelinedevelopment.org/handbook Updated October 2013. 


\section{Sterne 2017}

Sterne JA, Egger M, Moher D, Boutron I (editors). Chapter 10: Addressing reporting biases. In: Higgins JPT, Churchill R, Chandler J, Cumpston MS (editors), Cochrane Handbook for Systematic Reviews of Interventions version 5.2.0 (updated June 2017), Cochrane, 2017. Available from www.training.cochrane.org/handbook.

\section{Strong 2007}

Strong K, Mathers C, Bonita R. Preventing stroke: saving lives around the world. Lancet Neurology 2007;6:182-7.

\section{SWIFT PRIME 2015}

Saver JL, Goyal M, Bonafe A, Diener H-C, Levy El, Pereira VM, the SWIFT PRIME Investigators. Stent-retriever thrombectomy after intravenous t-PA vs. t-PA alone in stroke. New England Journal of Medicine 2015;372:2285-95.

\section{Wardlaw 2009}

Wardlaw JM, Murray V, Berge E, del Zoppo GJ. Thrombolysis for acute ischaemic stroke. Cochrane Database of Systematic Reviews 2009, Issue 4. [DOI: 10.1002/14651858.CD000213.pub2]

\section{References to other published versions of this review Bruins Slot 2011}

Bruins Slot KM, Berge E, O'Rourke K, Wardlaw JM. Percutaneous vascular interventions versus intravenous thrombolytic treatment for acute ischaemic stroke. Cochrane Database of Systematic Reviews 2011, Issue 9. [DOI: 10.1002/14651858.CD009292]

\section{CHARACTERISTICS OF STUDIES}

Characteristics of included studies [ordered by study ID]

Ducrocq 2005

\begin{tabular}{ll}
\hline Methods & Randomised, controlled, single-centre clinical trial \\
\hline Participants & - Age: $18-79$ years \\
- Neurological deficit present for $1 \mathrm{~h}$ and no improvement by the time of randomisation \\
- - Acute neurological deficit presumed to be due to cerebral ischaemia \\
- Moderate-severe deficit with a score on the SSS $\leq 50$
\end{tabular}

Interventions

Intervention group: thrombus disruption using microcatheter. Intra-arterial urokinase at a dose of $900,000 \mathrm{U}$

Control group: IV urokinase at a dose of 900,000 U

$\begin{array}{ll}\text { Outcomes } & \text { Primary outcome: mRS score } 0-2 \text { at } 90 \text { days' follow-up } \\ \text { Secondary outcomes: SSS score }>52 \text { on day } 90 \text {, Barthel Index score } \geq 85 \text { on day } 90 \text {, mean SSS score on } \\ \text { days } 7,30 \text { and } 90 \text {, mean Barthel Index on day } 90 \text {, and the number of participants discharged directly to } \\ \text { home }\end{array}$

Safety variables: overall mortality on day 90 , number of fatal and symptomatic non-fatal intracerebral haemorrhages, and other serious AEs

Notes The study was terminated early according to prespecified criteria because of high mortality rate (26\%)

\section{Risk of bias}

\begin{tabular}{lll}
\hline Bias & Authors' judgement & Support for judgement \\
\hline $\begin{array}{l}\text { Random sequence genera- } \\
\text { tion (selection bias) }\end{array}$ & Unclear risk & Randomisation procedure was not described \\
\hline $\begin{array}{l}\text { Allocation concealment } \\
\text { (selection bias) }\end{array}$ & Low risk & The trial was open-label \\
\hline $\begin{array}{l}\text { Blinding of participants } \\
\text { and personnel (perfor- } \\
\text { mance bias) }\end{array}$ & High risk & Participants and personnel were not blinded to treatment allocation \\
\hline
\end{tabular}

Percutaneous vascular interventions versus intravenous thrombolytic treatment for acute ischaemic stroke (Review) 
Ducrocq 2005 (Continued)

All outcomes

$\begin{array}{lll}\text { Blinding of outcome as- } & \text { High risk } & \text { Outcome assessors were not blinded to treatment allocation } \\ \text { sessment (detection bias) }\end{array}$

All outcomes

\begin{tabular}{lll}
\hline $\begin{array}{l}\text { Incomplete outcome data } \\
\text { (attrition bias) } \\
\text { All outcomes }\end{array}$ & Low risk & No loss to follow-up \\
\hline $\begin{array}{l}\text { Selective reporting (re- } \\
\text { porting bias) }\end{array}$ & Low risk & ITT analyses \\
\hline Other bias & Unclear risk & No \\
\hline
\end{tabular}

Sen 2009

\begin{tabular}{ll}
\hline Methods & Randomised, controlled, single-centre clinical trial \\
\hline Participants & Inclusion criteria \\
- Time of presentation $<3 \mathrm{~h}$ from symptom onset \\
- NIHSS $\geq 4$ or isolated aphasia or isolated hemianopsia \\
- Age $>18$ years \\
- Ability to provide written informed consent and comply with study assessments for the full duration \\
of the study
\end{tabular}

Interventions

Intervention group: mechanical thrombus disruption using microcatheter. Intra-arterial rtPA at a maximum dose of $20 \mathrm{mg}$. Concomitant heparin flush at $2 \mathrm{U}$ heparin/min

Control group: IV t-PA at a dose of $0.9 \mathrm{mg} / \mathrm{kg}$ (maximum, $90 \mathrm{mg}$ ), with $10 \%$ given as an initial bolus and the remaining $90 \%$ as a constant infusion over a period of $1 \mathrm{~h}$

Outcomes

The primary objective of the study was to test 3 areas that were deemed to be of importance in designing a future multicenter randomised trial:

- feasibility of randomisation, enrolment, and treatment within the given time frame specified

- an evaluation of safety variables and adverse events

- any trend of efficacy of the 2 forms of administration of rtPA, adjusting for baseline differences if necessary, which would be useful in designing a future study

Other outcomes: neurological improvement (reduction in NIHSS $\geq 4$ ) at 90 days; symptomatic and asymptomatic intracranial haemorrhages at $24 \mathrm{~h}$, TIMI recanalisation on MRI $24-72 \mathrm{~h}$

\begin{tabular}{lll}
\hline Notes & Feasibility study \\
\hline Risk of bias & \\
\hline Bias & Authors' judgement & Support for judgement \\
\hline $\begin{array}{l}\text { Random sequence genera- } \\
\text { tion (selection bias) }\end{array}$ & Low risk & $\begin{array}{l}\text { Computer-based random number generator (GraphPad Statmate, San Diego, } \\
\text { CA) }\end{array}$ \\
\hline $\begin{array}{l}\text { Allocation concealment } \\
\text { (selection bias) }\end{array}$ & Low risk & Open-label \\
\hline
\end{tabular}


Sen 2009 (Continued)

Blinding of participants High risk Participants and personnel were not blinded to treatment allocation and personnel (performance bias)

All outcomes

$\begin{array}{ll}\text { Blinding of outcome as- } & \text { Low risk }\end{array}$ Outcome assessors were blinded to treatment allocation

All outcomes

Incomplete outcome data Low risk

No loss to follow-up

(attrition bias)

All outcomes

\begin{tabular}{l}
$\begin{array}{l}\text { Selective reporting (re- Low risk } \\
\text { porting bias) }\end{array}$ \\
\hline
\end{tabular}

Other bias Unclear risk No

\section{SYNTHESIS Expansion 2013}

\begin{tabular}{ll}
\hline Methods & Randomised, controlled, multi-centre trial \\
\hline Participants & - Age 18-80 years \\
- Sudden focal neurological deficit attributable to a stroke & Clearly defined time of onset, allowing the initiation of IV treatment within $4.5 \mathrm{~h}$ of symptom onset and \\
intra-arterial treatment as soon as possible and within $6 \mathrm{~h}$ from symptom onset (having verified the \\
availability of the interventional neuroradiologist and taking into account all possible impediments)
\end{tabular}

Interventions

Intervention group: decided by interventional neuroradiologist. Either mechanical thrombus disruption using microcatheter, suction thrombectomy (Penumbra, Penumbra Inc), stenting (Solitaire, E3/ Covidien; Trevo, Concentric/Stryker), clot extraction by retrieval device (Merci, Concentric/Stryker). Intra-arterial rtPA at a dose of $0.9 \mathrm{mg} / \mathrm{kg}$ (maximum: $90 \mathrm{mg}$ ) could be given either alone or in addition to mechanical clot disruption. Concomitant heparin flush with $5000 \mathrm{U}$ bolus, followed by $500 \mathrm{U} / \mathrm{h}$

Control group: IV t-PA at a dose of $0.9 \mathrm{mg} / \mathrm{kg}$ (maximum: $90 \mathrm{mg}$ ), with 10\% given as an initial bolus and the remaining $90 \%$ as a constant infusion over a period of $1 \mathrm{~h}$

Outcomes Primary outcome: disability-free survival at 90 days, with freedom from disability defined as a mRS score 0-1

Secondary outcomes: proportion of participants with NIHSS score $\leq 6$

Safety measures: assessed at day 7 after thrombolysis: fatal and non-fatal symptomatic intracranial haemorrhage, fatal and non-fatal symptomatic oedema from an original brain infarction, fatal and non-fatal recurrent ischaemic stroke, death from any cause, neurologic deterioration (increase of $\geq 4$ points in the NIHSS score), and fatal and non-fatal extracerebral events

Notes

Risk of bias

\begin{tabular}{lll}
\hline Bias & Authors' judgement & Support for judgement \\
\hline $\begin{array}{l}\text { Random sequence genera- } \\
\text { tion (selection bias) }\end{array}$ & Low risk & $\begin{array}{l}\text { A single randomisation list was prepared with the use of a software system, } \\
\text { available at www.random.org/ }\end{array}$ \\
\hline
\end{tabular}


SYNTHESIS Expansion 2013 (Continued)

\begin{tabular}{lll}
$\begin{array}{l}\text { Allocation concealment } \\
\text { (selection bias) }\end{array}$ & Low risk & Open-label \\
\hline $\begin{array}{l}\text { Blinding of participants } \\
\text { and personnel (perfor- } \\
\text { mance bias) } \\
\text { All outcomes }\end{array}$ & Unclear risk & Participants and personnel were not blinded to treatment allocation \\
\hline $\begin{array}{l}\text { Blinding of outcome as- } \\
\text { sessment (detection bias) } \\
\text { All outcomes }\end{array}$ & Low risk & Outcome assessors were blinded to treatment allocation \\
\hline $\begin{array}{l}\text { Incomplete outcome data } \\
\text { (attrition bias) } \\
\text { All outcomes }\end{array}$ & Low risk & No loss to follow-up \\
\hline $\begin{array}{l}\text { Selective reporting (re- } \\
\text { porting bias) }\end{array}$ & Low risk & ITT analyses \\
\hline \begin{tabular}{l} 
Other bias \\
\hline
\end{tabular} & Unclear risk & No \\
\hline
\end{tabular}

\title{
SYNTHESIS Pilot 2010
}

\begin{tabular}{ll}
\hline Methods & Randomised, controlled, multi-centre trial \\
\hline Participants & - Age $18-80$ years \\
- Sudden focal neurological deficit attributable to a stroke & Clearly defined time of onset, allowing initiation of IV treatment within $3 \mathrm{~h}$ of symptom onset and in- \\
tra-arterial treatment as soon as possible and, in any case, within $6 \mathrm{~h}$ from symptom onset (having \\
verified the availability of the interventional neuroradiologist and taking into account all possible im- \\
pediments)
\end{tabular}

\begin{abstract}
Interventions
Intervention group: decided by interventional neuroradiologist. Either mechanical thrombus disruption using microcatheter, suction thrombectomy, clot extraction by retrieval device. Intra-arterial rtPA at a dose of $0.9 \mathrm{mg} / \mathrm{kg}$ (maximum: $90 \mathrm{mg}$ ) could be given either alone or in addition to mechanical clot disruption. Concomitant heparin flush with $2000 \mathrm{U}$ bolus, followed by $500 \mathrm{U}$ per hour
\end{abstract}

Control group: IV t-PA at a dose of $0.9 \mathrm{mg} / \mathrm{kg}$ (maximum: $90 \mathrm{mg}$ ), with 10\% given as an initial bolus and the remaining $90 \%$ as a constant infusion over a period of $1 \mathrm{~h}$
Outcomes
Primary outcomes: mRS score $0-2$ at 90 days' follow-up
Secondary outcomes: decrease in NIHSS, baseline to day 7; neurological deterioration ( $\geq 4$-point NIHSS) on day 7; any neurological deterioration during the first 7 days; all-cause death

\begin{tabular}{lll}
\hline Notes & Pilot study & \\
\hline Risk of bias & Authors' judgement & Support for judgement \\
\hline Bias & Low risk & $\begin{array}{l}\text { Random assignment to treatment was stratified per centre and prepared in a } \\
\text { ratio } 1: 1 \text { with casual numbers by a person not involved in the recruitment and } \\
\text { not operating in any of the recruiting centres. This person prepared opaque, } \\
\text { tion (selection bias) } \\
\text { sealed envelopes that were sequentially opened by the randomising investiga- } \\
\text { tors }\end{array}$
\end{tabular}


SYNTHESIS Pilot 2010 (Continued)

\begin{tabular}{|c|c|c|}
\hline $\begin{array}{l}\text { Allocation concealment } \\
\text { (selection bias) }\end{array}$ & Low risk & Open-label \\
\hline $\begin{array}{l}\text { Blinding of participants } \\
\text { and personnel (perfor- } \\
\text { mance bias) } \\
\text { All outcomes }\end{array}$ & High risk & Participants and personnel were not blinded to treatment allocation \\
\hline $\begin{array}{l}\text { Blinding of outcome as- } \\
\text { sessment (detection bias) } \\
\text { All outcomes }\end{array}$ & Low risk & Outcome assessors were blinded to treatment allocation \\
\hline $\begin{array}{l}\text { Incomplete outcome data } \\
\text { (attrition bias) } \\
\text { All outcomes }\end{array}$ & Low risk & No loss to follow-up \\
\hline $\begin{array}{l}\text { Selective reporting (re- } \\
\text { porting bias) }\end{array}$ & Low risk & ITT analyses \\
\hline Other bias & Unclear risk & No \\
\hline
\end{tabular}

AE: adverse event; ITT: intention-to-treat; IV: intravenous; MRI: magnetic resonance imaging; mRS: modified Rankin Scale; NIHSS: National Institutes of Health Stroke Scale; rtPA: recombinant tissue plasminogen activator; SSS: Scandinavian Stroke Scale; t-PA: tissue plasminogen activator; TIMi: Thombolysis In Myocardial Infarction; U: units

Characteristics of excluded studies [ordered by study ID]

\begin{tabular}{ll}
\hline Study & Reason for exclusion \\
\hline Del Zoppo 1998 & Control group did not receive IV thrombolytic medication \\
\hline Furlan 1999 & Control group did not receive IV thrombolytic medication \\
\hline Ogawa 2007 & Control group did not receive IV thrombolytic medication \\
\hline
\end{tabular}

IV: intravenous

Characteristics of ongoing studies [ordered by study ID]

\section{NCT01455935}

Trial name or title

"WASSABI"


NCT01455935 (Continued)

- IV rtPA

- best medical therapy (no thrombolysis or percutaneous vascular interventions)

\begin{tabular}{ll}
\hline Outcomes & Primary outcome: mRS score 0-2 at 90 days' follow-up \\
\hline Starting date & November 2011 \\
\hline Contact information & $\begin{array}{l}\text { Tareq Kass-Hout, MD, Jacobs Neurological Institute, University of Buffalo, Buffalo, New York, USA. } \\
\text { E-mail: kasshouttareq@gmail.com }\end{array}$ \\
\hline
\end{tabular}

Notes

Number of participants to be enrolled: 90

Estimated study completion: unknown; study protocol required changes after recent trials of endovascular treatment for acute ischaemic stroke (Tareq Kass-Hout, personal communication, September 2017)

Clinicaltrials.gov identifier: NCT01455935

CT: computed tomography; IV: intravenous; mRS: modified Rankin Scale; NIHSS: National Institutes of Health Stroke Scale; rtPA: recombinant tissue plasminogen activator

\section{DATA AND ANALYSES}

Comparison 1. Percutaneous vascular interventions versus intravenous thrombolytic treatment for acute ischaemic stroke

\begin{tabular}{|c|c|c|c|c|}
\hline Outcome or subgroup title & No. of studies & $\begin{array}{l}\text { No. of partici- } \\
\text { pants }\end{array}$ & Statistical method & Effect size \\
\hline 1 Modified Rankin scale score $0-2$ & 3 & 443 & $\begin{array}{l}\text { Risk Ratio (M-H, Fixed, 95\% } \\
\mathrm{Cl})\end{array}$ & $1.01[0.82,1.25]$ \\
\hline $\begin{array}{l}2 \text { Modified Rankin scale score, contin- } \\
\text { uous }\end{array}$ & 3 & 443 & $\begin{array}{l}\text { Mean Difference (IV, Fixed, } \\
95 \% \mathrm{CI} \text { ) }\end{array}$ & $-0.43[-0.81,-0.04]$ \\
\hline $\begin{array}{l}3 \text { All-cause death at the end of fol- } \\
\text { low-up }\end{array}$ & 3 & 443 & $\begin{array}{l}\text { Risk Ratio (M-H, Fixed, 95\% } \\
\mathrm{Cl})\end{array}$ & $1.34[0.84,2.14]$ \\
\hline 4 All-cause death within 14 days & 2 & 416 & $\begin{array}{l}\text { Risk Ratio (M-H, Fixed, 95\% } \\
\mathrm{Cl})\end{array}$ & $1.32[0.69,2.51]$ \\
\hline $\begin{array}{l}5 \text { Symptomatic intracranial haemor- } \\
\text { rhages within first } 14 \text { days }\end{array}$ & 4 & 450 & $\begin{array}{l}\text { Risk Ratio (M-H, Fixed, 95\% } \\
\mathrm{Cl})\end{array}$ & $0.99[0.50,1.95]$ \\
\hline
\end{tabular}

Analysis 1.1. Comparison 1 Percutaneous vascular interventions versus intravenous thrombolytic treatment for acute ischaemic stroke, Outcome 1 Modified Rankin scale score 0-2.

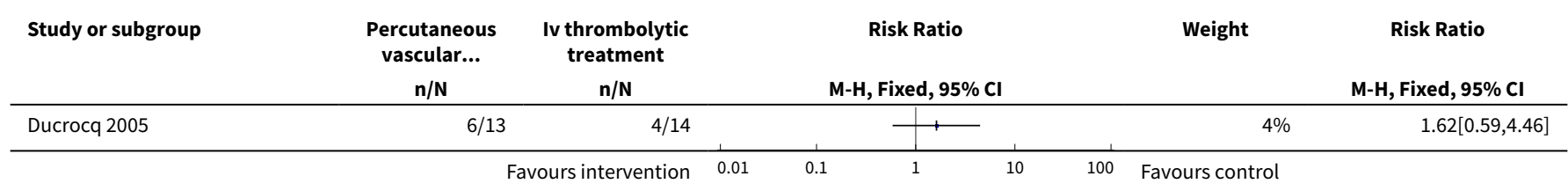




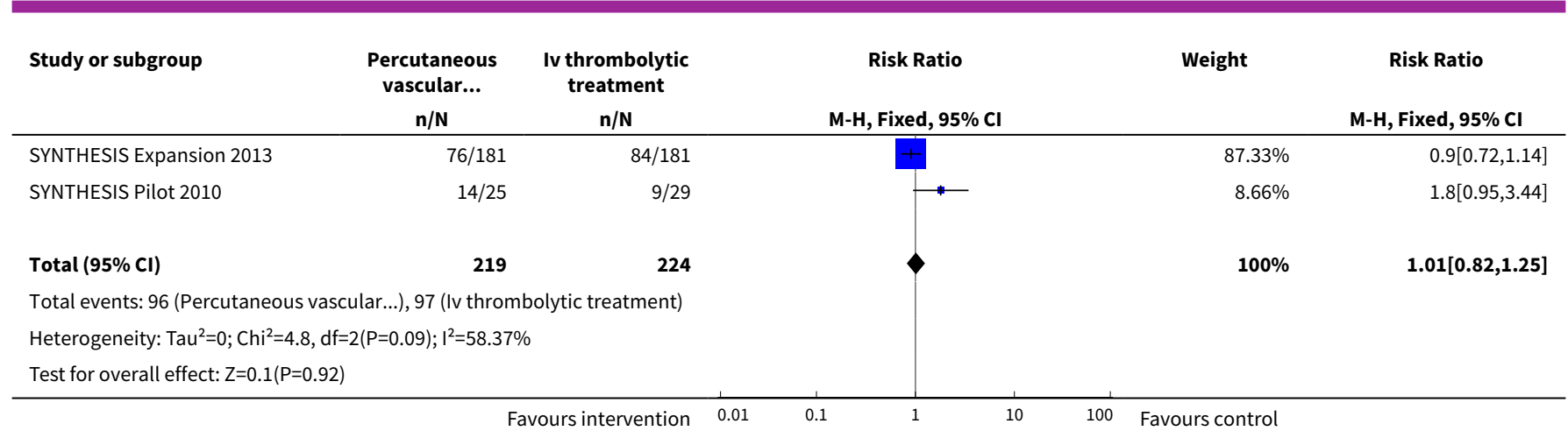

\section{Analysis 1.2. Comparison 1 Percutaneous vascular interventions versus intravenous thrombolytic treatment for acute ischaemic stroke, Outcome 2 Modified Rankin scale score, continuous.}

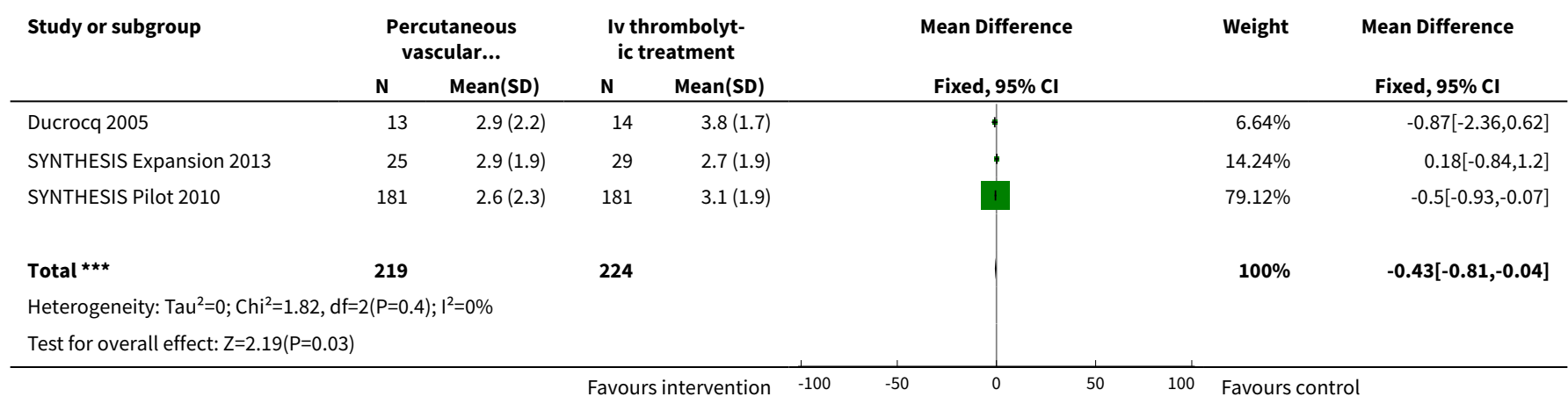

Analysis 1.3. Comparison 1 Percutaneous vascular interventions versus intravenous thrombolytic treatment for acute ischaemic stroke, Outcome 3 All-cause death at the end of follow-up.

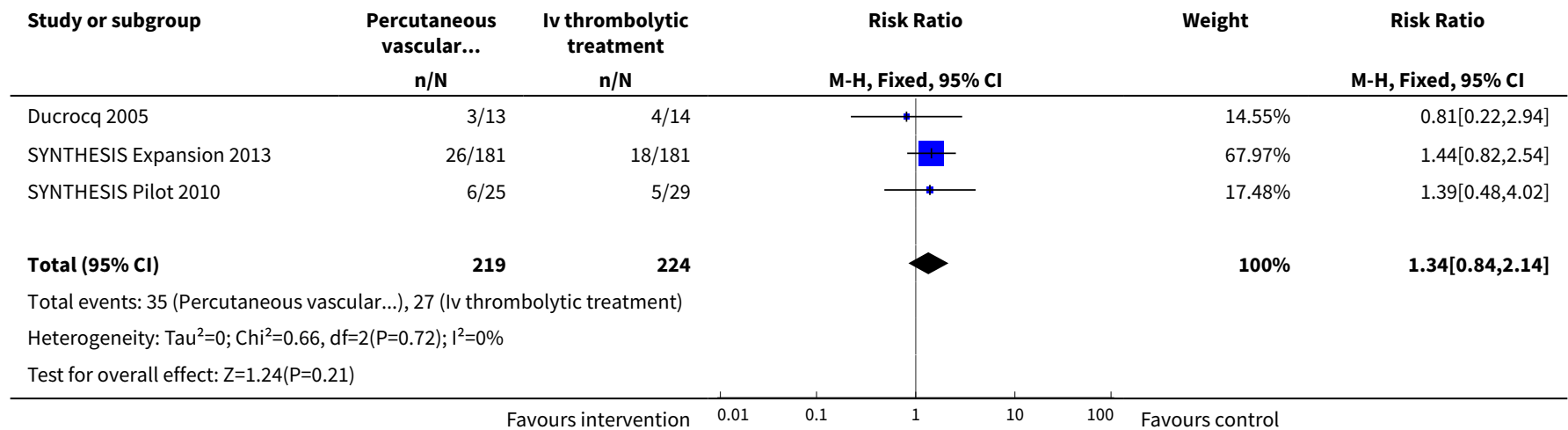


Analysis 1.4. Comparison 1 Percutaneous vascular interventions versus intravenous thrombolytic treatment for acute ischaemic stroke, Outcome 4 All-cause death within 14 days.

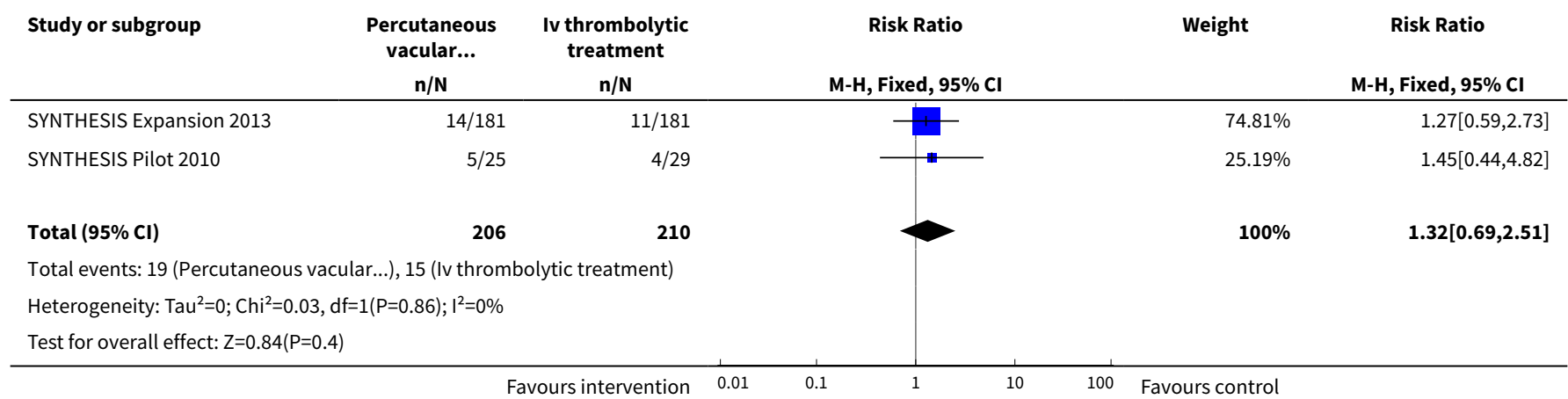

\section{Analysis 1.5. Comparison 1 Percutaneous vascular interventions versus intravenous thrombolytic treatment for acute ischaemic stroke, Outcome 5 Symptomatic intracranial haemorrhages within first 14 days.}

\begin{tabular}{|c|c|c|c|c|c|}
\hline Study or subgroup & $\begin{array}{c}\text { Percutaneous } \\
\text { vascular... } \\
\text { n/N } \\
\end{array}$ & $\begin{array}{c}\text { Iv thrombolytic } \\
\text { treatment } \\
n / N\end{array}$ & M-H, Fixed, 95\% Cl & Weight & $\begin{array}{c}\text { Risk Ratio } \\
\text { M-H, Fixed, 95\% Cl }\end{array}$ \\
\hline Ducrocq 2005 & $2 / 13$ & $0 / 14$ & & $3.11 \%$ & $5.36[0.28,102.12]$ \\
\hline Sen 2009 & $0 / 3$ & $1 / 4$ & 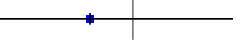 & $8.59 \%$ & $0.42[0.02,7.71]$ \\
\hline SYNTHESIS Expansion 2013 & $10 / 181$ & $10 / 181$ & - & $64.43 \%$ & $1[0.43,2.34]$ \\
\hline SYNTHESIS Pilot 2010 & $2 / 25$ & $4 / 29$ & $\longrightarrow$ & $23.86 \%$ & $0.58[0.12,2.9]$ \\
\hline Total $(95 \% \mathrm{Cl})$ & 222 & 228 & & $100 \%$ & $0.99[0.5,1.95]$ \\
\hline \multicolumn{6}{|c|}{ Total events: 14 (Percutaneous vascular...), 15 (Iv thrombolytic treatment) } \\
\hline \multicolumn{6}{|c|}{ Heterogeneity: $\mathrm{Tau}^{2}=0 ; \mathrm{Chi}^{2}=2.02, \mathrm{df}=3(\mathrm{P}=0.57) ; \mathrm{I}^{2}=0 \%$} \\
\hline Test for overall effect: $Z=0.04$ & & & & & \\
\hline
\end{tabular}

\section{AP PE N DICES}

\section{Appendix 1. Cochrane Central Register of Controlled Trials (CENTRAL)}

1. [mh ^"cerebrovascular disorders"] or [mh ^"basal ganglia cerebrovascular disease"] or [mh "brain ischemia"] or [mh ^"carotid artery diseases"] or [mh ^"carotid artery thrombosis"] or [mh ^"intracranial arterial diseases"] or [mh ^"cerebral arterial diseases"] or [mh "intracranial embolism and thrombosis"] or [mh stroke]

2. isch ${ }^{\star} e \mathrm{mi}^{\star}$ near/6 (stroke* or apoplex* or cerebral next vasc ${ }^{\star}$ or cerebrovasc ${ }^{\star}$ or cva)

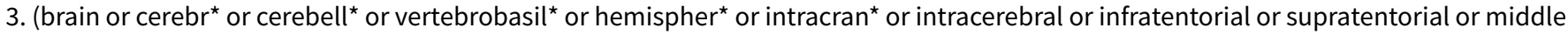
next cerebr ${ }^{\star}$ or mca* or "anterior circulation") near $/ 5$ (isch" emi $^{\star}$ or infarct* or thrombo* or emboli* or occlus* or hypoxi ${ }^{\star}$ )

4. \#1 or \#2 or \#3

5. [mh ^"radiography, interventional"] or [mh ^"radiology, interventional"]

6. [mh ^catheterization] or [mh ^angioplasty] or [mh ^"angioplasty, balloon"] or [mh ^"angioplasty, balloon, laser-assisted"] or [mh

^"angioplasty, laser"] or [ $\mathrm{mh}^{\wedge}$ atherectomy] or [mh^"balloon dilatation"] or [mh ^"catheter ablation"]

7. [mh^ ^ Stents]

8. [mh^ $\wedge^{\wedge}$ thrombectomy] or [mh^embolectomy]

9. [mh^"blood vessel prosthesis"] or [mh^"blood vessel prosthesis implantation"]

10. [mh ${ }^{\wedge}$ "Cerebral Revascularization"] or [mh ^reperfusion] or [mh ^dilatation]

11. interventional near/3 (radiolog* or radiograph* or neuroradiolog*)

12. angioplast* or stent $^{\star}$

13. thrombectomy or embolectomy or atherect* 
14. thromboaspiration or arterial next recanali*ation

15. (mechanical or radiolog* or pharmacomechanical or laser or endovascular or neurovascular) near/5 (thrombolys ${ }^{\star}$ or reperfusion or fragment* or aspiration or recanali*ation or clot next lys $\left.{ }^{\star}\right)$

16. (clot or thrombus or thrombi or embol ${ }^{\star}$ ) near/5 (aspirat ${ }^{\star}$ or remov* or retriev* or fragment ${ }^{\star}$ or retract ${ }^{\star}$ or extract $^{\star}$ or obliterat* or dispers $\left.{ }^{\star}\right)$

17. (retrieval or extraction) near/5 device*

18. "endoluminal repair ${ }^{\star} "$

19. blood vessel near/5 (prosthesis or implantat*)

20. (merci or concentric) next retriever

21. endovascular next snare* or neuronet or microsnare or "X-ciser" or angiojet

22. [mh ^ultrasonics] or [mh ^"ultrasonic therapy"] or [mh ^ultrasonography] or [mh "ultrasonography, Doppler"] or [mh

$\wedge$ "ultrasonography, interventional"]

23. ultrasound ${ }^{\star}$ or ultrasonic ${ }^{\star}$ or ultrasonogra* or sonograph* or insonation

24. (transcranial near/5 doppler) or TCD or TCCD

25. [mh/US].

26. sonothrombolysis or sonothromboly* or sonolys* or sonothrombotripsy or thrombotripsy

27. $\{$ OR \#5-\#26\}

28. [mh^"thrombolytic therapy"]

29. [mh ^"fibrinolytic agents"] or [mh ^plasmin] or [mh^plasminogen] or [mh^"tissue plasminogen activator"] or [mh "plasminogen activators"] or [mh^"urokinase-type plasminogen activator"]

30. [mh ^fibrinolysis]

31. thromboly* or fibrinoly* or recanalis* or recanaliz*

32. (clot ${ }^{\star}$ or thrombus) near/5 (lyse or lysis or dissolve* or dissolution)

33. tPA or t-PA or rtPA or rt-PA or plasminogen or plasmin or alteplase or actilyse

34. anistreplase or streptodornase or streptokinase or urokinase or pro*urokinase or rpro*uk or lumbrokinase or duteplase or lanoteplase or pamiteplase or reteplase or saruplase or staphylokinase or streptase

35 . \#28 or \#29 or \#30 or \#31 or \#32 or \#33 or \#34

36. \#4 and \#27 and \#35

\section{Appendix 2. MEDLINE (Ovid) search strategy}

1. cerebrovascular disorders/ or basal ganglia cerebrovascular disease/ or exp brain ischemia/ or carotid artery diseases/ or carotid artery thrombosis/ or intracranial arterial diseases/ or cerebral arterial diseases/or exp "intracranial embolism and thrombosis"/ or exp stroke/

2. (isch?emi\$ adj6 (stroke\$ or apoplex\$ or cerebral vasc\$ or cerebrovasc\$ or cva)).tw.

3. ( (brain or cerebr $\$$ or cerebell\$ or vertebrobasil\$ or hemispher $\$$ or intracran $\$$ or intracerebral or infratentorial or supratentorial or middle cerebr\$ or mca\$ or anterior circulation) adj5 (isch?emi\$ or infarct\$ or thrombo $\$$ or emboli\$ or occlus\$ or hypoxi\$)).tw.

4. 1 or 2 or 3

5. radiography, interventional/ or radiology, interventional/

6. catheterization/ or angioplasty/ or angioplasty, balloon/ or angioplasty, balloon, laser-assisted/ or angioplasty, laser/ or atherectomy/ or balloon embolectomy/ or catheter ablation/

7. stents/

8. thrombectomy/or embolectomy/ or mechanical thrombolysis/

9. blood vessel prosthesis/ or blood vessel prosthesis implantation/

10. cerebral revascularization/ or reperfusion/ or dilatation/

11. (interventional adj3 (radiolog\$ or radiograph\$ or neuroradiolog\$)).tw.

12. (angioplast\$ or stent\$).tw.

13. (thrombectomy or embolectomy or atherect\$).tw.

14. thromboaspiration.tw.

15. ((mechanical or radiolog\$ or pharmacomechanical or laser or endovascular or neurovascular) adj5 (thrombolys\$ or reperfusion or fragmentation or aspiration or recanali?ation or clot lys\$)).tw.

16. ((clot or thrombus or thrombi or embol\$) adj5 (aspirat\$ or remov\$ or retriev\$ or fragmentation or retract\$ or extract\$ or obliterat\$ or dispers\$)).tw.

17. ((retrieval or extraction) adj5 device\$).tw.

18. endoluminal repair\$.tw.

19. ((blood vessel or artery) adj5 (prosthesis or implantat\$)).tw.

20. ((merci or concentric) adj retriever).tw.

21. (endovascular snare\$ or neuronet or microsnare or X-ciser or angiojet).tw.

22. ultrasonics/ or ultrasonic therapy/ or ultrasonography/ or exp ultrasonography, doppler/ or ultrasonography, interventional/

23. (ultrasound\$ or ultrasonic $\$$ or ultrasonogra\$ or sonograph\$ or insonation).tw.

24. ((transcranial adj5 doppler) or TCD or TCCD).tw.

25. ultrasonography.fs.

26. thrombolytic therapy/ 
27. fibrinolytic agents/ or plasmin/ or plasminogen/ or tissue plasminogen activator/ or exp plasminogen activators/ or urokinase-type plasminogen activator/

28. fibrinolysis/

29. (thromboly\$ or fibrinoly\$ or recanalis\$ or recanaliz\$ or sonolys\$).tw.

30. ((clot\$ or thrombus) adj5 (lyse or lysis or dissolve or dissolution or fragment\$)).tw.

31. (tPA or t-PA or rtPA or rt-PA or plasminogen or plasmin or alteplase or actilyse).tw.

32. (anistreplase or streptodornase or streptokinase or urokinase or pro? urokinase or rpro?uk or lumbrokinase or duteplase or lanoteplase or pamiteplase or reteplase or saruplase or staphylokinase or streptase).tw.

33. (sonothrombolysis or sonothromboly\$ or sonothrombotripsy or thrombotripsy).tw.

34. or/22-33

35. infusions, intra-arterial/

36. (intra arterial or intra-arterial or intraarterial or IA).tw.

37. 35 or 36

38. 34 and 37

39.5 or 6 or 7 or 8 or 9 or 10 or 11 or 12 or 13 or 14 or 15 or 16 or 17 or 18 or 19 or 20 or 21 or 38

40.4 and 39

41. Randomized Controlled Trials as Topic/

42. random allocation/

43. Controlled Clinical Trials as Topic/

44. control groups/

45. clinical trials as topic/ or clinical trials, phase i as topic/ or clinical trials, phase ii as topic/ or clinical trials, phase iii as topic/ or clinical trials, phase iv as topic/

46. double-blind method/

47. single-blind method/

48. therapies, investigational/

49. randomized controlled trial.pt.

50. controlled clinical trial.pt.

51. (clinical trial or clinical trial phase i or clinical trial phase ii or clinical trial phase iii or clinical trial phase iv).pt.

52. (random\$ or RCT or RCTs).tw.

53. (controlled adj5 (trial\$ or stud\$)).tw.

54. (clinical\$ adj5 trial\$).tw.

55. ((control or treatment or experiment\$ or intervention) adj5 (group\$ or subject\$ or patient\$)).tw.

56. (quasi-random\$ or quasi random $\$$ or pseudo-random $\$$ or pseudo random\$).tw.

57. ((singl\$ or doubl\$ or tripl\$ or trebl\$) adj5 (blind\$ or mask\$)).tw.

58. trial.ti

59. or/41-58

60.40 and 59

61. exp animals/ not humans.sh

62. (carotid or hemorrhag $\$$ or haemorrhag\$ or aneurysm $\$$ or fibrillation or trauma $\$$ or aort $\$$ or coronary or myocardial).ti.

63.60 not (61 or 62)

\section{Appendix 3. Embase (Ovid) search strategy}

1. cerebrovascular disease/ or cerebral artery disease/ or cerebrovascular accident/ or stroke/ or vertebrobasilar insufficiency/ or carotid artery disease/ or exp carotid artery obstruction/ or exp brain infarction/ or exp brain ischemia/ or exp occlusive cerebrovascular disease/ or stroke patient/ or stroke unit/

2. (isch?emi\$ adj6 (stroke\$ or apoplex\$ or cerebral vasc\$ or cerebrovasc\$ or cva or attack\$)).tw.

3. ( (brain or cerebr\$ or cerebell\$ or vertebrobasil\$ or hemispher $\$$ or intracran $\$$ or intracerebral or infratentorial or supratentorial or middle cerebr\$ or mca\$ or anterior circulation) adj5 (isch?emi\$ or infarct\$ or thrombo or emboli\$ or occlus\$ or hypoxi\$)).tw.

4. 1 or 2 or 3

5. interventional radiology/ or endovascular surgery/

6. percutaneous transluminal angioplasty/ or angioplasty/ or laser angioplasty/ or catheterization/ or catheter ablation/ or balloon dilatation/ or exp atherectomy/

7. stent/

8. thrombectomy/ or exp percutaneous thrombectomy/ or embolectomy/

9. artery prosthesis/

10. cerebral revascularization/ or reperfusion/ or artery dilatation/ or recanalization/

11. (interventional adj3 (radiolog\$ or radiograph\$ or neuroradiolog\$)).tw.

12. (angioplast\$ or stent\$).tw.

13. (thrombectomy or embolectomy or atherect\$).tw.

14. (thromboaspiration or arterial recanali?ation).tw. 
15. ((mechanical or radiolog\$ or pharmacomechanical or laser or endovascular or neurovascular) adj5 (thrombolys\$ or reperfusion or fragment\$ or aspiration or recanali?ation or clot lys\$)).tw.

16. ((clot or thrombus or thrombi or embol\$) adj5 (aspirat\$ or remov\$ or retriev\$ or fragment\$ or retract\$ or extract\$ or obliterat\$ or dispers\$)).tw.

17. ((retrieval or extraction) adj5 device\$).tw.

18. endoluminal repair\$.tw.

19. ((blood vessel or artery) adj5 (prosthesis or implantat\$)).tw.

20. ((merci or concentric) adj retriever).tw.

21. (endovascular snare\$ or neuronet or microsnare or X-ciser or angiojet).tw.

22. ultrasound/ or exp ultrasound therapy/ or echography/ or doppler echography/ or intravascular ultrasound/

23. (ultrasound\$ or ultrasonic $\$$ or ultrasonogra or sonograph\$ or insonation).tw.

24. ((transcranial adj5 doppler) or TCD or TCCD).tw.

25. (sonothrombolysis or sonothromboly\$ or sonolys\$ or sonothrombotripsy or thrombotripsy).tw.

26. or $/ 5-25$

27. fibrinolytic therapy/

28. fibrinolytic agent/ or plasmin/ or plasminogen/ or exp plasminogen activator/

29. blood clot lysis/

30. fibrinolysis/

31. (thromboly\$ or fibrinoly\$ or recanalis\$ or recanaliz\$).tw.

32. ((clot\$ or thrombus) adj5 (lyse or lysis or dissolve\$ or dissolution)).tw.

33. (tPA or t-PA or rtPA or rt-PA or plasminogen or plasmin or alteplase or actilyse).tw.

34. (anistreplase or streptodornase or streptokinase or urokinase or pro?urokinase or rpro?uk or lumbrokinase or duteplase or lanoteplase or pamiteplase or reteplase or saruplase or staphylokinase or streptase).tw.

35. or/27-34

36. Randomized Controlled Trial/

37. Randomization/

38. Controlled Study/

39. control group/

40. clinical trial/ or phase 1 clinical trial/ or phase 2 clinical trial/ or phase 3 clinical trial/ or phase 4 clinical trial/ or controlled clinical trial/

41. Double Blind Procedure/

42. Single Blind Procedure/ or triple blind procedure/

43. random\$.tw.

44. (controlled adj5 (trial\$ or stud\$)).tw.

45. (clinical\$ adj5 trial\$).tw.

46. ((control or treatment or experiment\$ or intervention) adj5 (group\$ or subject\$ or patient\$)).tw.

47. (quasi-random $\$$ or quasi random\$ or pseudo-random $\$$ or pseudo random\$).tw.

48. ((singl\$ or doubl\$ or tripl\$ or trebl\$) adj5 (blind\$ or mask\$)).tw.

49. (coin adj5 (flip or flipped or toss\$)).tw.

50. (latin square or versus or controls).tw.

51. or/36-50

52. 4 and 26 and 35 and 51

53. limit 52 to human

\section{Appendix 4. Other databases}

"Intra arterial" or "Percutaneous vascular interventions" or "endovascular" or "thrombectomy"

AND

"intravenous"

AND

"stroke"

WHAT'S NEW

\begin{tabular}{lll}
\hline Date & Event & Description \\
\hline 6 November 2018 & Amended & Minor corrections to search methods \\
\hline
\end{tabular}




\section{CONTRIBUTIONS OF AUTHORS}

HL: guarantor for the review, acquisition of data, analyses, drafting of the review

EB: acquisition of data, analyses, design of the review, drafting of protocol and review

KBS and JW: drafting of protocol, commenting on protocol and review drafts

All co-authors revised the review for intellectual content.

\section{DECLARATIONS OF INTEREST}

Haakon Lindekleiv: none known

Eivind Berge: none known

Karsten Bruins Slot: KBS is currently employed by F. Hoffmann-La Roche (Roche Norge AS). The data included in this review are based on research which has had no influence or involvement by F. Hoffmann-La Roche by any means. The views expressed in this review are the personal views of KBS and should not be understood or quoted as being made on behalf of or reflecting the position of F. Hoffmann-La Roche.

Joanna M Wardlaw: none known

\section{SOURCES OF SUPPORT}

\section{Internal sources}

- No sources of support supplied

\section{External sources}

- South-Eastern Norway Regional Health Authority, Norway.

Educational grant

\section{DIFFERENCES BETWEEN PROTOCOLANDREVIEW}

The protocol defined that we should include "participants with a definite ischaemic stroke confirmed by either a computerised tomography (CT) or magnetic resonance imaging (MRI) scan, who are eligible for treatment with an intravenous thrombolytic agent or a percutaneous vascular intervention, or both". We included participants with acute ischaemic stroke based on the individual trials' definition of ischaemic stroke.

We did not search Google Scholar because it did not understand the expert search strings and was unable to translate them. We did not search Cochrane Peripheral Vascular Diseases' Trials Register, as we considered Cochrane Stroke's Trials Register adequate for identifying possible trials.

During the work on this review, Current Controlled Trials (www.controlled-trials.com), changed its name to ISRCTN. However, the website states that the ISRCTN trial search is under review and not available. We searched Current Controlled Trials up to September 2016. Searching Current Controlled Trials did not yield references not found in other databases. As ISRCTN was not available, we excluded it as a database in our review.

\section{N DEX TERMS}

\section{Medical Subject Headings (MeSH)}

*Thrombectomy [instrumentation] [methods]; Carotid Artery Thrombosis [drug therapy] [surgery]; Infarction, Middle Cerebral Artery [drug therapy] [surgery]; Intracranial Hemorrhages [epidemiology]; Outcome Assessment, Health Care; Randomized Controlled Trials as Topic; Stroke [ ${ }^{\star}$ drug therapy] [etiology] [mortality] [ ${ }^{\star}$ surgery]; Thrombolytic Therapy [ ${ }^{\star}$ methods]

\section{MeSH check words}

Aged; Female; Humans; Male; Middle Aged 